\title{
Interdecadal weakening of the cross-equatorial flows over the Maritime Continent during the boreal summer in the mid-1990s: drivers and physical processes
}

\author{
Xiaoxuan Zhao ${ }^{1,3} \cdot$ Buwen Dong ${ }^{2}$ (I) $\cdot$ Riyu Lu ${ }^{1,3}$ \\ Received: 10 July 2020 / Accepted: 4 February 2021 / Published online: 18 February 2021 \\ (c) The Author(s) 2021
}

\begin{abstract}
In this study, the cross-equatorial flows (CEF) on both high and low level (HCEF/LCEF) troposphere over the Maritime Continent (MC) in boreal summer are found to have experienced an interdecadal weakening in the mid-1990s based on both JRA55 and NCEP reanalyses. The outputs of 8 coupled models in CMIP6 are used to investigate drivers and the corresponding mechanisms. Model results show that the role of external forcing is weak in the interdecadal weakening of CEF. By contrast, the observed interdecadal weakening of both HCEF and LCEF can be largely explained by internal variability associated with a negative phase of the interdecadal Pacific Oscillation (IPO). Associated with negative IPO are anomalous divergence (convergence), enhanced precipitation over MC and anomalous cyclonic (anticyclonic) circulations, reduced precipitation over western North Pacific (WNP) in the upper (lower) troposphere. Sensitivity experiments based on MetUMGA6 further manifest that this IPO phase transition can lead to the interdecadal weakening of CEF, in which the central tropical Pacific (CTP) sea surface temperature (SST) anomalies play a dominant role. The cold SST anomalies in CTP lead to reduced local convection and trigger enhanced convection over MC through changes in the Walker circulation. The enhanced convection over MC leads to a change in local Hadley circulation over the western Pacific sector. This change is characterized by anomalous ascents over MC, southerlies in the upper troposphere, descents and reduced precipitation over WNP and northerlies in the lower troposphere, leading to the weakening of CEF. Meanwhile, positive SST anomalies over MC associated with negative IPO also make a contribution to the weakening of CEF by inducing a change in the Hadley circulation in the western Pacific sector through similar processes.
\end{abstract}

Keywords Cross-equatorial flows · Interdecadal weakening · Interdecadal Pacific Oscillation · CMIP6 · External forcing · Internal variability

Buwen Dong

buwen.dong@ncas.ac.uk

1 State Key Laboratory of Numerical Modeling for Atmospheric Sciences and Geophysical Fluid Dynamics, Institute of Atmospheric Physics, Chinese Academy of Sciences, Beijing 100029, China

2 Department of Meteorology, National Centre for Atmospheric Science, University of Reading, Reading, UK

3 College of Earth and Planetary Sciences, University of Chinese Academy of Sciences, Beijing 100049, China

\section{Introduction}

In boreal summer, several channels of airflows across the equator from the Southern to Northern Hemisphere can be found within tropical areas in the lower troposphere (Shi et al. 2007; Wang and Yang 2008; Li and Li 2014), which are named as the cross-equatorial flows (CEFs). Among these, CEFs adjacent to the Maritime Continent (MC) show high correlations with each other on the interannual timescale and thus collectively referred to as the MC-CEF (hereafter abbreviate to CEF).

As one of important components of the East Asian Summer Monsoon (EASM) (Zeng and Li 2002), CEF plays a fundamental role in transporting moisture from the Southern Hemisphere to Northern Hemisphere (Wang and Li 1982; Lau and Li 1984). Variation of CEF is also generally 
considered to be closely related to the climate variability over the East Asian monsoon region and western North Pacific (WNP). For example, strong CEF coincides with reduced (enhanced) rainfall in Yangtze and Huai River Basin (South China) (Han and He 2002; Zhu 2012). Meanwhile, it can help maintaining the WNP monsoon trough (Lin and Chou 2014) and modulating the activities of tropical cyclones (Xu 2011; Zhao et al. 2012; Feng et al. 2017).

East Asian Summer Monsoon (EASM) is well documented to have undergone two interdecadal changes around late 1970s and early 1990s (Hu 1997; Yu and Zhou 2007; Liu et al. 2012; Lin et al. 2016; Cheng et al. 2020). Thus, as an important component of EASM, what is the variation of CEF on the interdecadal timescale? Cong et al. (2007) investigated one channel of $\mathrm{CEF}$ around $105^{\circ} \mathrm{E}$ based on NCEP reanalysis (1958-2005) and found it experienced an interdecadal strengthening in mid 1970s. Zeng et al. (2011) found that $\mathrm{CEF}$ in the channel around $120^{\circ} \mathrm{E}$ and $150^{\circ} \mathrm{E}$ showed an opposite interdecadal change in 1970s based on ERA40, but showed a consistent change in NCAR CAM3 model simulations forced by prescribed sea surface temperature (SST). Zhu (2012) analyzed the CEF averaged over $100-140^{\circ} \mathrm{E}$ based on NCEP reanalysis (1948-2010), and indicated that the CEF underwent two interdecadal changes, one in the late 1970s and one in the late 1990s. However, the physical mechanisms responsible for these interdecadal changes of CEF remain unclear.

Besides, it is worth noting that CEF is not limited in the lower troposphere, strong branches in the upper troposphere have been found by previous works (Zeng and $\mathrm{Li}$ 2002; Gao and Xue 2006; Shi et al. 2007), characterized as strong northerlies in the boreal summer climatology. Zhao and $\mathrm{Lu}$ (2020) further proposed that the variation of the upper-level CEF is closely related to that in the lower level on the interannual timescale. Thus, what is the interdecadal variability of the upper-level CEF? Is it consistent with that of CEF in the lower troposphere? Importantly, what are the physical processes that are responsible for the interdecadal variations?

Considering the data length restriction, it is hard to analyze the interdecadal variation only based on reanalysis datasets. Meanwhile, the observed interdecadal change is generally influenced by both external forcings and internal variability. Given these issues, the outputs of both historical and piControl simulations of CMIP6 (Eyring et al. 2016) are used here.

This paper aims to investigate the interdecadal change of CEF in both the upper and lower troposphere and explore the corresponding physical processes and mechanisms. Section 2 shows the reanalysis data, model simulations, and methods used in this study. Section 3 displays the observed recent interdecadal change of upper- and lower-level CEF. Section 4 discusses the role of external forcing, while Sect. 5 focuses on the internal variability. Section 6 shows the sensitivity experiments designed to help understanding the mechanisms. Finally, Sect. 7 devotes conclusions and discussions.

\section{Data, model simulations and methods}

\subsection{Data}

In this study, we first investigate the observed interdecadal change of CEF by using following monthly reanalysis datasets: JRA55 (Kobayashi et al. 2015; Harada et al. 2016) and NCEP/NCAR (Kalnay et al. 1996) for zonal and meridional winds; NOAA's precipitation reconstruction dataset (Chen et al. 2002) for precipitation; Hadley Centre Sea Ice and Sea Surface Temperature dataset (HadISST; Rayner 2003) for SST; and the sea level pressure (SLP) is also obtained from JRA55. All these variables cover at least the period of 1975-2014, and our analyses are applied to the boreal summer, described as the average of June, July and August (JJA).

\subsection{Model simulations}

CMIP6 historical simulations with both time-dependent all external forcings (ALL) and single forcing for greenhouse gases (GHG), anthropogenic aerosol (AA) and natural forcing (NAT) are used in this study. The all-forcing historical simulation in each model covers the period of 1850-2014, while those single forcing simulations extend to 2020 . Ensemble mean of the multimodel historical simulations represents the climatic responses to the external forcings. Meanwhile, CMIP6 piControl simulations with constant forcings (details can be referred to Eyring et al. 2016) are also used in this study. Considering that the external forcings keep constant, the only source of variability in piControl is the internal variability. Given the different run lengths for piControl experiments in different models, we select the last 500 years of each model simulations. It should be noted that only models which contain all simulations and variables mentioned above will be picked, and finally there are eight models available (shown in Table 1). All models have 3-dimensional outputs at 19 pressure levels extending from 1000 to $1 \mathrm{hPa}$, and model simulations are interpolated to a common grid with a horizontal resolution of $2.5^{\circ} \times 2.5^{\circ}$ before the analysis.

The latest Met Office atmosphere and land model GA6.0 (MetUM-GA6), documented in Walters et al. (2017), is used in this study to perform some sensitivity experiments. This model adopts the resolution of $1.875^{\circ}$ longitude by $1.25^{\circ}$ 
Table 1 CMIP6 models used in this study

\begin{tabular}{|c|c|c|c|c|c|c|c|}
\hline & \multirow[t]{2}{*}{ Model } & \multirow{2}{*}{$\begin{array}{l}\text { Resolution } \\
\text { (lat } \times \text { lon) }\end{array}$} & \multicolumn{4}{|c|}{ Historical Members } & \multirow{2}{*}{$\begin{array}{l}\text { piControl r1i1p } \\
\text { (choose last } 500 \\
\text { yrs) }\end{array}$} \\
\hline & & & All & GHG & AA & NAT & \\
\hline 1 & BCC-CSM2-MR & $160 \times 320$ & 3 & 3 & 3 & 3 & 600 \\
\hline 2 & CanESM5 & $64 \times 128$ & 25 & 10 & 10 & 10 & 1000 \\
\hline 3 & CNRM-CM6-1 & $128 \times 256$ & 10 & 10 & 10 & 10 & 500 \\
\hline 4 & IPSL-CM6A-LR & $143 \times 144$ & 9 & 10 & 10 & 10 & 1200 \\
\hline 5 & MIROC6 & $128 \times 256$ & 10 & 3 & 3 & 3 & 800 \\
\hline 6 & HadGEM3-GC31-LL & $145 \times 192$ & 4 & 4 & 4 & 4 & 500 \\
\hline 7 & MRI-ESM2-0 & $160 \times 320$ & 5 & 3 & 3 & 3 & 701 \\
\hline 8 & GISS-E2-1-G & $90 \times 144$ & 10 & 5 & 5 & 5 & 851 \\
\hline
\end{tabular}

latitude and 85 levels in the vertical. The experimental designs will be shown in Sect. 6.

\subsection{Methods}

Following Zhao and Lu (2020), the high-level CEF index (HCEFI) is defined as $200 \mathrm{hPa}$ meridional wind along the equator averaged over $110^{\circ}-170^{\circ} \mathrm{E}$, and the low-level CEF index (LCEFI) is defined at $925 \mathrm{hPa}$, averaged over $102.5^{\circ}-110^{\circ} \mathrm{E}, 122.5^{\circ}-130^{\circ} \mathrm{E}$ and $147.5^{\circ}-152.5^{\circ} \mathrm{E}$. It should be noticed that positive anomaly of HCEFI represents the weakening of the high-level CEF, since northerlies prevail on the high level in boreal summer climatology.

A 9-year running average is applied to remove the signal of the interannual variation and high frequency oscillation of CEF. The moving $t$ test is used to identify the significant interdecadal change of both HCEFI and LCEFI in observations and piControl simulations (Miao et al. 2020), and the corresponding changes between two subperiods of other variables are examined by the Student's $t$ test. Meanwhile, the consistency among individual cases identified in the piControl simulations is evaluated to verify the robustness of the multi-cases ensemble. It is measured by the percentage that the decadal change of each case shows same sign with that of the multi-cases ensemble (MCE) mean. Consistency among piControl simulations in each model is also considered. Meanwhile, the cross-correlation is adopted in this study. The effective degree of freedom for the filtered time series is calculated as $\mathrm{N} \frac{1-\mathrm{r} 1 \times \mathrm{r} 2}{1+\mathrm{r} 1 \times \mathrm{r} 2}$, where $\mathrm{N}$ represents the number of sample, $\mathrm{r} 1$ and $\mathrm{r} 2$ represent the lag-one autocorrelation for each series. More details can be well referred to Bretherton et al. (1999). Besides, a 5-point area-weighted smoothing is applied to the sensitivity experiment results to filter some variability in small spatial scale.

\section{Observed recent interdecadal weakening of CEF}

The time series of HCEFI anomaly and its 9-year running average based on JRA55 reanalysis over 1958-2016 are shown in Fig. 1a. It reveals that the HCEFI undergoes three phase changes from weak to strong and then to weak. The moving $t$-test with a subperiod of 20 years is used to detect the significant shift and it shows that the minimum ( 0.1 significance level) appears in 1994 (Fig. 1b), which suggests the significant interdecadal weakening around the mid-1990s. This interdecadal weakening of HCEFI is also supported by NCEP reanalysis (Fig. 1a and b), suggesting the weakening of high level CEF in the mid-1990s is a robust feature.

The interdecadal weakening during 1975-2014 can also be found in two datasets for LCEFI (Fig. 1c and d). These analyses indicate that a coherent interdecadal variation of CEF in both the upper and lower troposphere occurred in the mid-1990s in observations. The spatial variations associated with the interdecadal weakening of CEF are investigated by the differences between two periods 1995-2014 (P2) and 1975-1994 (P1) and they are illustrated in Fig. 2 for JRA55 reanalysis. Spatial patterns of changes based on NCEP reanalysis give similar results (not shown).

Corresponding changes of the horizontal circulation at $200 \mathrm{hPa}$ and $925 \mathrm{hPa}$ (Fig. 2a and b) show strong southerly (northerly) anomalies over MC, consistent with the weakening of the upper- (lower-) level CEF. These meridional wind anomalies are mainly associated with anomalous upper-level (lower-level) divergence (convergence), low SLP anomalies over the MC (Fig. 2d), and anomalous lower-level anticyclonic circulation, high SLP anomalies over the subtropical western North Pacific (WNP). Associated with these large-scale circulation anomalies are interdecadal changes in precipitation (Fig. 2c) that exhibit a meridional dipole pattern with decreases over WNP and increases over MC. These changes in circulation and precipitation suggest that the interdecadal weakening of CEF is closely related to changes in local Hadley circulation within the western 
(a) HCEFI

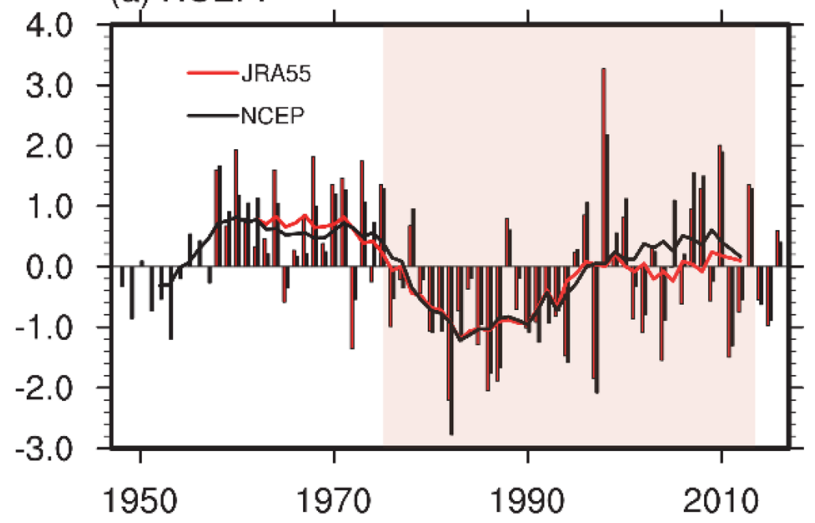

(b) 20-yr moving t-test

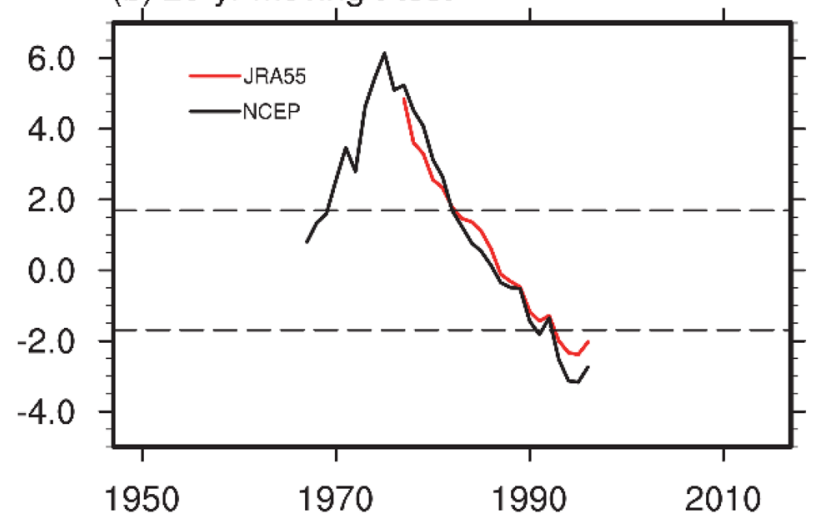

Fig. 1 a HCEFI $\left(\mathrm{m} \mathrm{s}^{-1}\right)$ anomaly time series (bars) and its decadal component (9-year running average; lines) for period of 1958-2016 based on JRA55 reanalysis (red), and 1948-2016 based on NCEP reanalysis (black). The anomalies are relative to the climatology of

tropical Pacific sector. A zonal contrast of precipitation changes can also be found, characterized by increases over $\mathrm{MC}$ and decreases over the central-western Pacific (CWP). This zonal contrast of precipitation changes is associated with anomalous easterlies in the lower troposphere and westerlies in the upper troposphere, indicating an enhancement of the Walker circulation (Fig. 2a and b). Corresponding changes in SSTs show large-scale warm anomalies over the Indo-Pacific, central North Pacific, central South Pacific and Atlantic and weak/cold anomalies over the eastern Pacific (Fig. 2e, f). This pattern of SST changes bears a strong similarity to the interdecadal Pacific Oscillation (IPO), which underwent a transition from positive to negative phase in around late-1990s based on observations (Parker et al. 2007; Dai 2012; Henley et al. 2015; Hua et al. 2018).

The results in observations (reanalyses) indicate that the recent interdecadal weakening of CEF is closely related to changes in local Hadley circulation over the western tropical Pacific sector and an enhancement of the Walker circulation in the tropical Pacific. These circulation changes are (c) LCEFI

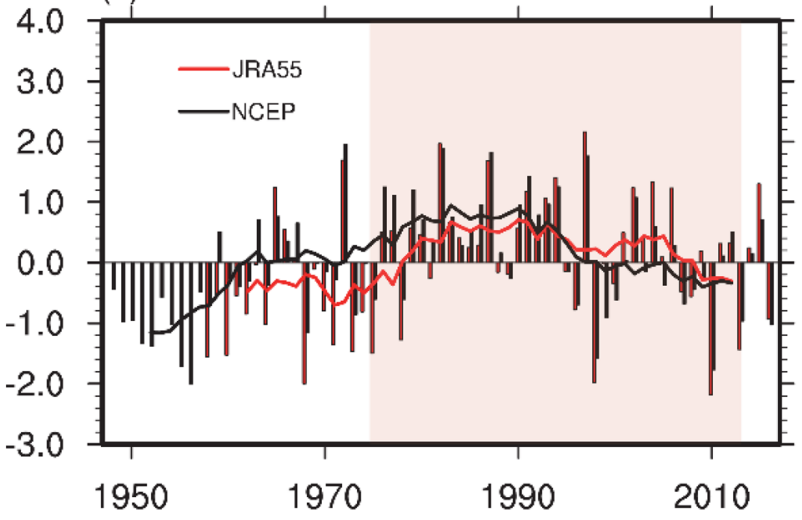

(d) 20-yr moving t-test

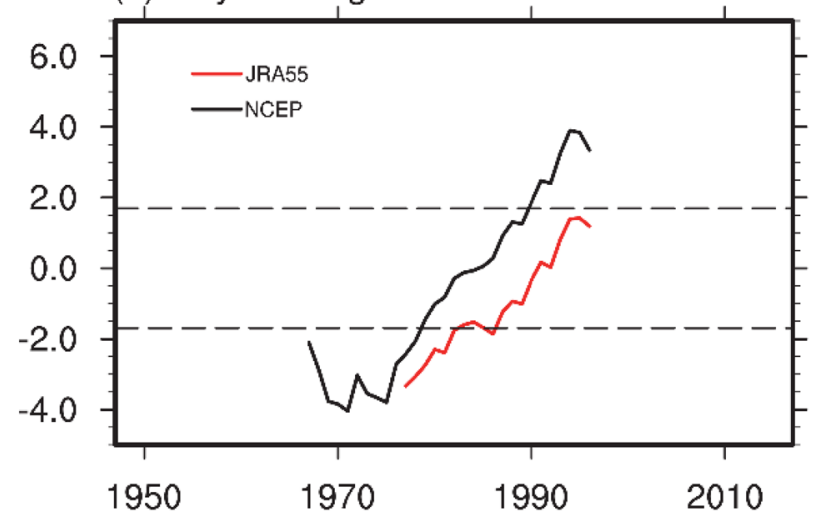

whole period. b Moving $t$ test (subseries as 20 years; lines) and the 0.1 significance level (dashed lines). c-d Are same as (a-b), but for LCEFI

associated with a negative phase of IPO. Implied linkage between the Walker circulation and IPO is consistent with Dong and Lu (2013).

However, drivers and detailed physical processes are hard to disseminate since the observed interdecadal change is result of the combination of external forcing and internal variability. In following sections, CMIP6 multi-models are adopted to investigate the respective role of external forcings and internal variability in this interdecadal weakening of $\mathrm{CEF}$ and a set of sensitivity experiments is used to elucidate physical processes involved.

\section{The role of external forcing}

The performance of selected CMIP6 models (Table 1) in simulating the climatology of the upper- and lower-level CEF is shown in Fig. 3, together with the results based on JRA55 reanalysis. Main features in the reanalysis are strong northeasterlies at $200 \mathrm{hPa}$ over the tropical western Pacific, 
Fig. 2 Spatial patterns of differences in JJA between two periods 1995-2014 (P2) and 1975-1994 (P1) based on different datasets. a Wind fields $\left(\mathrm{m} \mathrm{s}^{-1}\right.$; uv: vector; v: shading) at $200 \mathrm{hPa}, \mathbf{b}$ at $925 \mathrm{hPa}$ based on JRA55 reanalysis, c precipitation $\left(\mathrm{mm} \mathrm{day}^{-1}\right)$ based on NOAA precipitation reconstruction, $\mathbf{d}$ sea level pressure (SLP; hPa) based on JRA55 reanalysis, and e sea surface temperature (SST; ${ }^{\circ} \mathrm{C}$ ) based on HadISST. $\mathbf{f}$ is same as (e), but with the global mean of SST removed to emphasize regional pattern and SST gradients. Dots represent regions where differences are significant at the $95 \%$ confidence level based on the Student's $t$ test. For better identifying the significant change of CEF (characterized by the meridional wind), only the $\mathrm{v}$ winds in $(\mathbf{a}, \mathbf{b})$ are tested

Fig. 3 Climatological wind fields ( $\mathrm{m} \mathrm{s}^{-1}$; uv: vector; v: shading) at a $200 \mathrm{hPa}, \mathbf{b}$ $925 \mathrm{hPa}$ in JJA for period of 1975-2014 based on JRA55 reanalysis. c-d are same as (a, b), but based on the MME mean of the historical simulations in selected CMIP6 models. For better comparison with model simulations, wind fields in JRA55 (with horizontal resolution of $1.25^{\circ} \times 1.25^{\circ}$ ) are interpolated to $2.5^{\circ} \times 2.5^{\circ}$
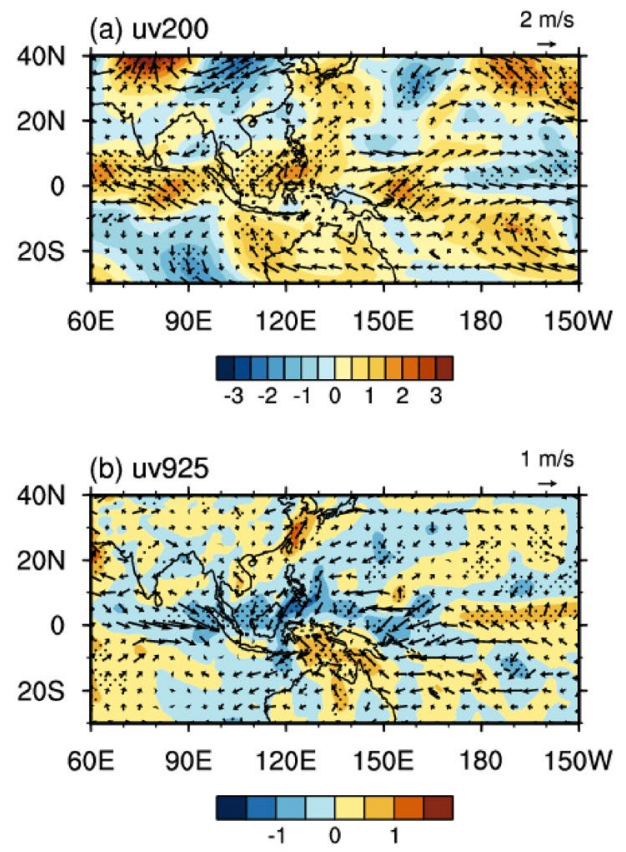

(c) Precip

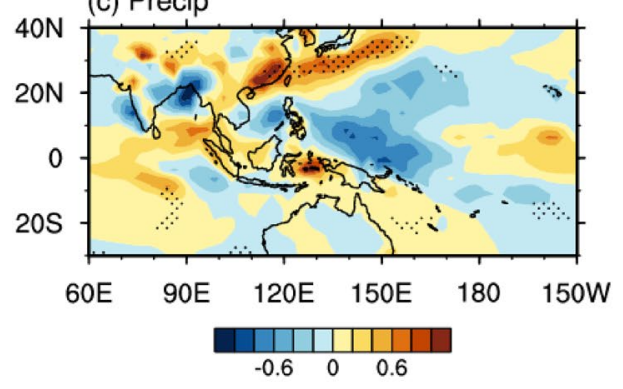

(a) $200 \mathrm{hPa}$

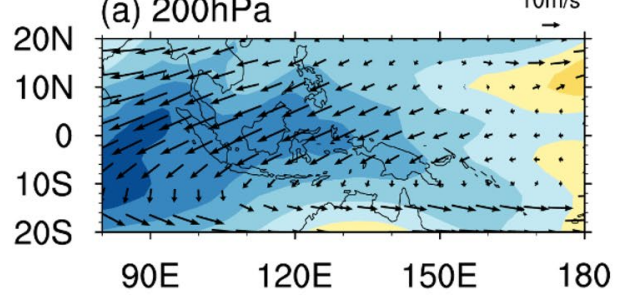

(b) $925 \mathrm{hPa}$

$5 \mathrm{~m} / \mathrm{s}$

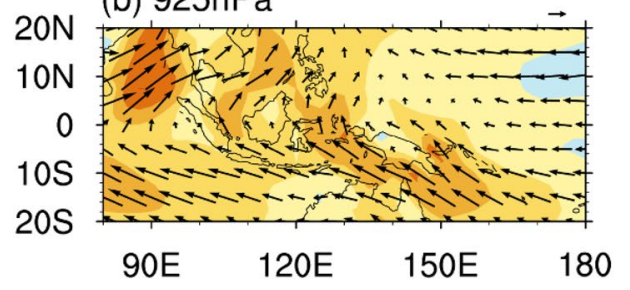

(d) SLP

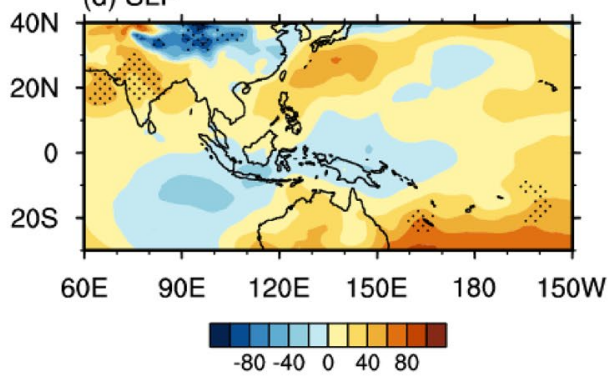

(e) SST

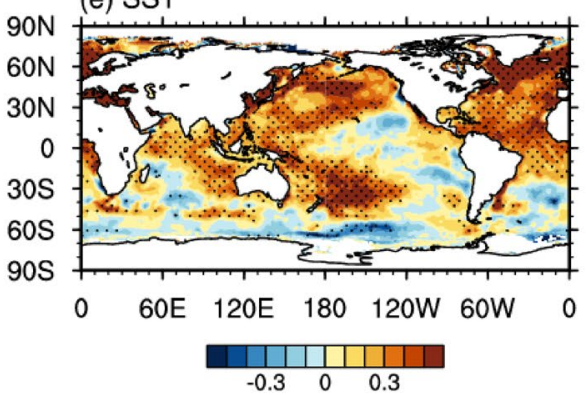

(f) SST minus global mean

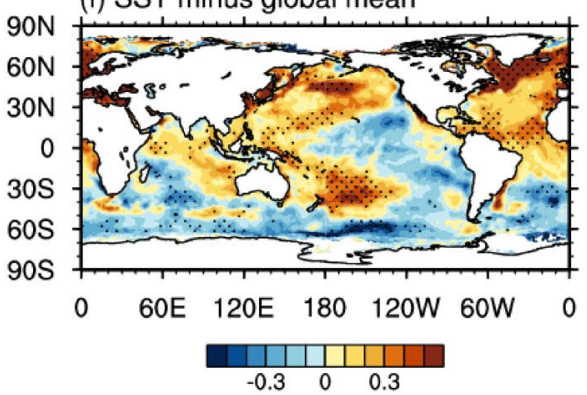

(c) $200 \mathrm{hPa}$
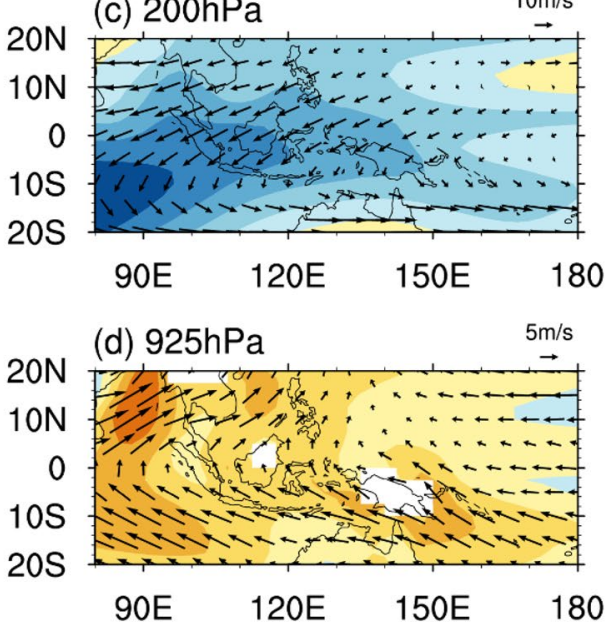
especially over the region of $\mathrm{HCEFI}\left(110^{\circ}-170^{\circ} \mathrm{E}\right)$. In the lower level, strong southeasterlies prevail in the southern subtropics and they turn northward in the tropics with strong CEFs in several channels separated by the topography of MC (Fig. 3a, b). These spatial distributions of winds in both the upper and lower troposphere are well captured by the multimodel ensemble (MME) mean (Fig. 3c, d), although the intensity in model simulations is a little bit weak. As for individual models, about half models underestimate the intensity of CEF, while others overestimate (not shown).

The interdecadal change of the HCEFI between two periods 1995-2014 and 1975-1994 (P2-P1) in MME mean forced by all external forcings is calculated and compared with that in JRA55 (Fig. 4a). This figure shows that the role of all forcings only explains $6.9 \%$ of the interdecadal weakening in the reanalysis. It is, therefore, suggesting that all forcing changes are unlikely to be the main driver of the observed recent interdecadal weakening of CEF. The changes of HCEFI from single forcings due to changes in AA, GHG and NAT are calculated, and the results also indicate weak contributions from individual forcing changes (Fig. 4a). Analyses of the LCEFI show similar results (Fig. 4b).

The spatial patterns of MME mean changes between two periods (P2-P1) for various variables in response to changes in all forcings are illustrated in Fig. 5. Figure 5a shows that the interdecadal changes of meridional winds in large regions over MC are very weak, and the associated circulation only reflects as a weak cyclonic circulation anomaly over Southeast Asia in the upper troposphere. For the lower level (Fig. 5b), the meridional winds show opposite changes in different channels, which offset each other and lead to the total change of LCEFI to be almost close to zero (Fig. 4b). These weak changes of circulation in the upper and lower troposphere are associated with weak cross equatorial SLP gradients (Fig. 5d) over the western tropical Pacific and weak changes of precipitation (Fig. 5c).
SST changes (Fig. 5e) under all forcings present significant warming on the global scale, which show large differences with SST anomalies associated with the weakening of CEF in observations (Fig. 2e). The spatial pattern of SST anomalies with global mean removed (Fig. 5f) does not bear a similarity to the negative IPO phase.

Why do MME mean simulates a weak response of CEF in both upper and lower troposphere? Are the weak responses due to large spread of responses in different models or different model ensemble members? This question is addressed by investigating changes of CEF in individual model ensemble members. Figure 6 illustrates the results of single model ensemble (SME) means, which are also known to well estimate the forced signal even with few ensemble members (Kravtsov and Callicutt 2017; Frankcombe et al. 2018). These SME means show that eight models do not show fully consistent changes under the given external forcings, which suggests the different model responses to the same external forcing changes. Opposite responses can lead to the offset between different models when MME mean is calculated. These analyses indicate that almost all SME means fail to explain $30 \%$ of the observed changes, suggesting that external forcings are unlikely to be the main driver of the interdecadal weakening of CEF during the last four decades in observations.

Although the MME mean CEF responses or SME mean responses to external forcing changes are weak, the interdecadal changes in each member of eight CMIP6 models (Fig. 6) show strong diversity. Some of them show similar magnitudes of changes as seen in observations but other members show similar magnitudes of changes with opposite signs. These results indicate the important role of the internal variability and imply that observed interdecadal weakening of CEF might be likely the result of the internal variability. Considering the interdecadal weakening of CEF being associated with negative IPO phase in observations, changes of CEF and IPO indexes between
Fig. 4 a Interdecadal changes of HCEFI $\left(\mathrm{m} \mathrm{s}^{-1}\right)$ in JRA55 between two periods (P2-P1), MME mean responses to changes in all-forcings (ALL), anthropogenic aerosol (AA), greenhouse gases (GHG) and natural forcing (NAT). The error bar represents the standard error of intermodal variability. $\mathbf{b}$ is same as (a), but for LCEFI (a) HCEF P2-P1

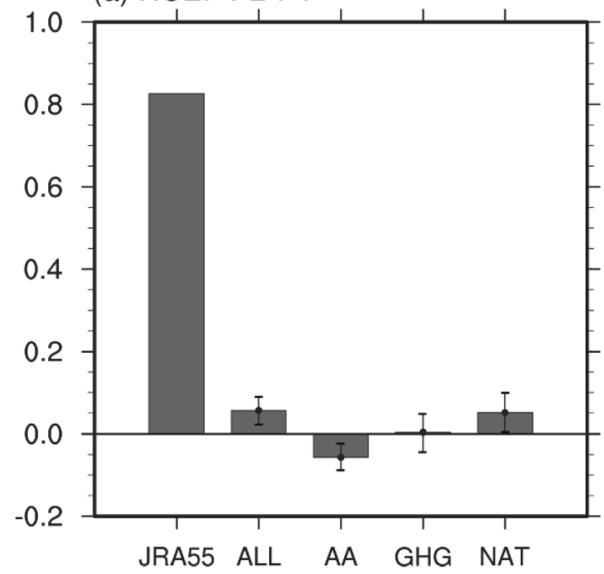

(b) LCEF P2-P1

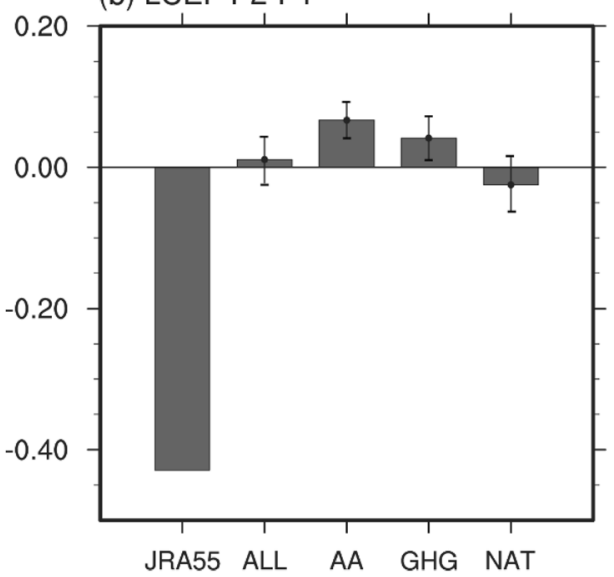


Fig. 5 Spatial patterns of differences in JJA between two periods (P2-P1) based on the MME mean of all-forcing historical simulations. a Wind fields ( $m$ $\mathrm{s}^{-1}$; uv: vector; v: shading) at $200 \mathrm{hPa}, \mathbf{b}$ at $925 \mathrm{hPa}$, c precipitation $\left(\mathrm{mm} \mathrm{day}^{-1}\right)$, $\mathbf{d}$ sea level pressure (SLP; $\mathrm{hPa}$ ), and e sea surface temperature (SST; $\left.{ }^{\circ} \mathrm{C}\right)$. $\mathbf{f}$ is same as (e), but with the global mean of SST removed. Dots represent regions where differences are significant at the $95 \%$ confidence level based on the Student's $t$ test. For better identifying the significant change of CEF (characterized by the meridional wind), only the $\mathrm{v}$ winds in $(\mathbf{a}, \mathbf{b})$ are tested

Fig. 6 a Observed interdecadal change of HCEFI $\left(\mathrm{m} \mathrm{s}^{-1}\right)$, and those simulated by MME mean, SME means and each member under all external forcings. For easy distinguishing the members in different models, black and white bars are used alternately. Dashed lines represent the $30 \%$ of the observed change. b is same as (a), but for LCEFI
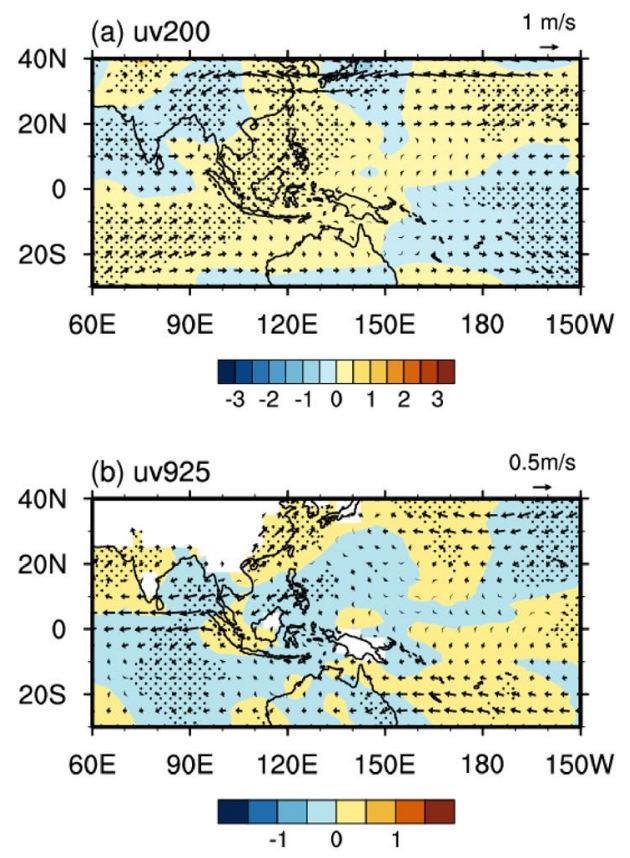

(c) Precip

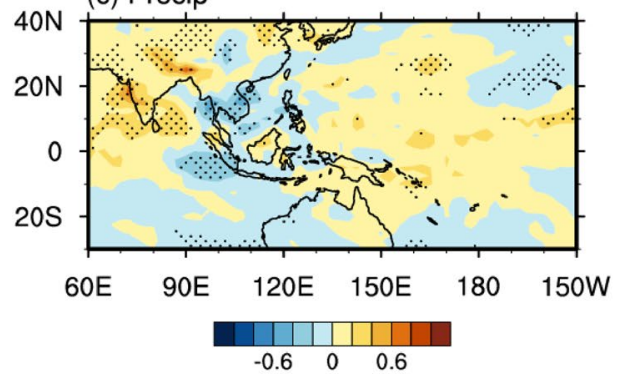

(d) SLP

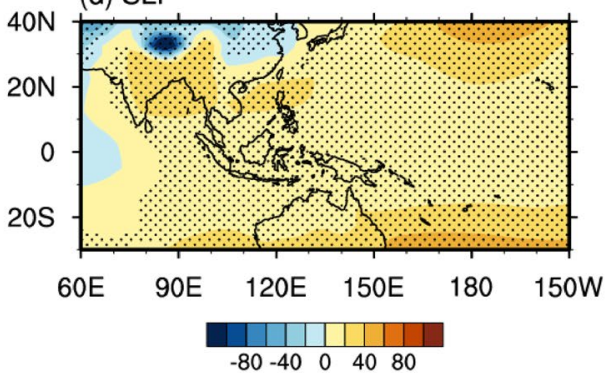

(e) SST

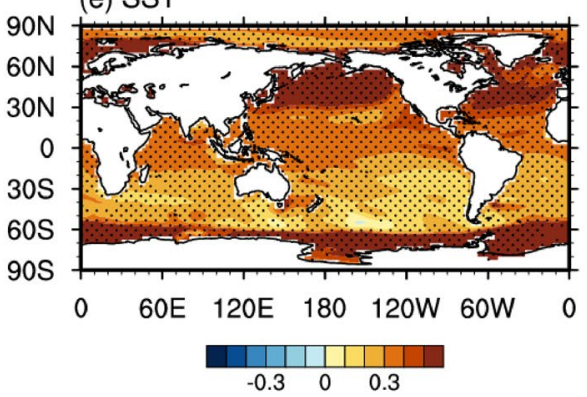

(f) SST minus global mean

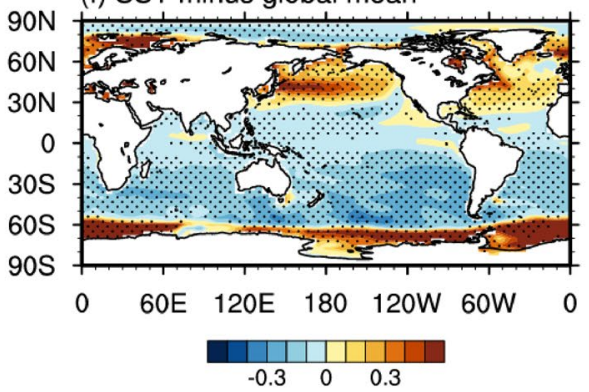

(a) HCEF P2-P1

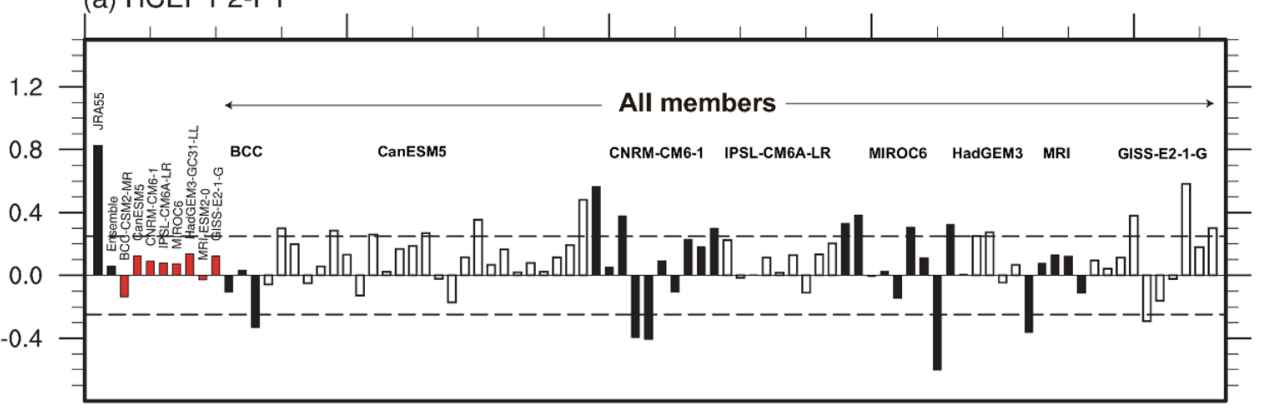

(b) LCEF P2-P1

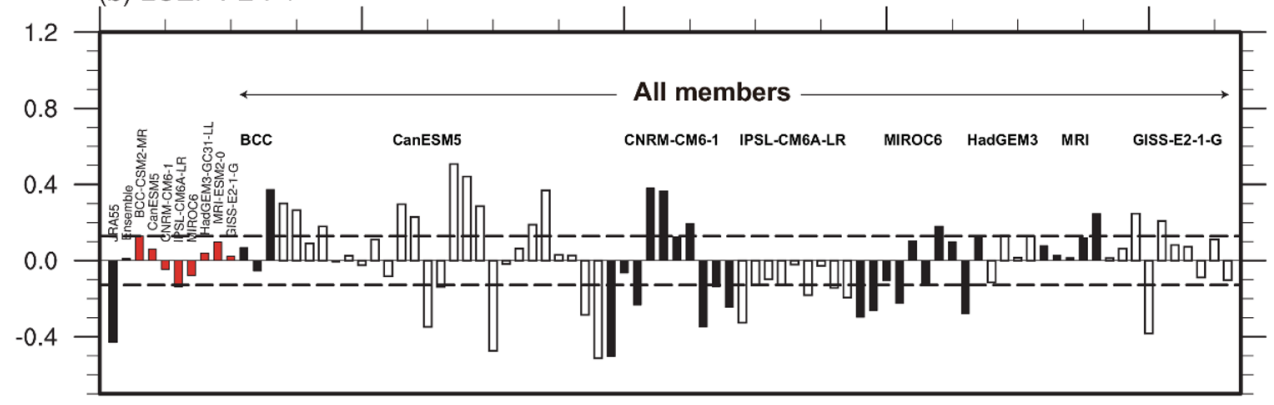


1995-2014 and 1975-1994 based on historical simulations for each member is also discussed (Fig. S1). The definition of IPO index follows Henley et al. (2015), for which the area averaged SSTs in three key regions, i.e., $25-45^{\circ} \mathrm{N}$, $140^{\circ} \mathrm{E}-145^{\circ} \mathrm{W}(\mathrm{T} 1) ; 10^{\circ} \mathrm{S}-10^{\circ} \mathrm{N}, 170^{\circ} \mathrm{E}-90^{\circ} \mathrm{W}(\mathrm{T} 2)$; and $50-15^{\circ} \mathrm{S}, 150^{\circ} \mathrm{E}-160^{\circ} \mathrm{W}$ (T3), are used. The index is defined as $\mathrm{T} 2-\frac{1}{2}(\mathrm{~T} 1+\mathrm{T} 3)$. Strong diversity of CEF changes can be found associated with the large spread of IPO changes with large weakening (strengthening) of CEF being related to large negative (positive) IPO indexes and weak changes of CEF being related to weak changes in IPO indexes. The results imply that the large spread of model simulated CEF changes between two periods among different ensemble members in historical simulations might resulted from the large spread of model simulated IPO changes which in turn reflect a dominant role of internal variability.

\section{The role of internal variability}

In order to investigate internal interdecadal variability of CEF, time series of HCEF and LCEF indices in boreal summer are calculated based on piControl simulations. The interdecadal weakening and strengthening cases for both HCEF and LCEF are identified by using the moving $t$ test (0.1 significance level) on these two indices with the subperiod of 20 years. Note that the time interval between two cases in the same time series is not less than 40 years using this method. As shown in Table 2, 33 (26) interdecadal weakening cases are selected for HCEF (LCEF) from eight piControl simulations.

The time evolutions (the 9-year running average) of these selected interdecadal weakening cases based on both HCEFI and LCEFI and their multi case ensemble (MCE) means are illustrated in Fig. 7. For easy comparison,
Table 2 Number of weakening and strengthening cases picked in each model piControl simulation for HCEFI and LCEFI
Fig. 7 Time evolutions of interdecadal weakening cases (unit: $\mathrm{m} \mathrm{s}^{-1}$ ) selected from the eight piControl simulations in CMIP6 models by moving $t$-test, and there are 33 (26) cases according to HCEFI (LCEFI). a 9-year running average of HCEFI depicted by cases according to HCEFI (grey lines) and their multi case ensemble (MCE) mean (black line). b is same as (a), but for LCEFI depicted by cases according to LCEFI. Red lines in $(\mathbf{a}, \mathbf{b})$ are HCEFI and LCEFI for period of 1975-2014 based on JRA55 reanalysis. c is same as (a), but by cases according to LCEFI. Dashed black line is a copy of black line in (a). $\mathbf{d}$ is same as (b), but by cases according to HCEFI. Dashed black line is a copy of black line in (b)

\begin{tabular}{|c|c|c|c|c|c|}
\hline & \multirow[t]{2}{*}{ Model } & \multicolumn{2}{|l|}{$\mathrm{HCEF}$} & \multicolumn{2}{|l|}{ LCEF } \\
\hline & & Weakening & Strengthening & Weakening & Strengthening \\
\hline 1 & BCC-CSM2-MR & 6 & 6 & 4 & 5 \\
\hline 2 & CanESM5 & 8 & 7 & 5 & 4 \\
\hline 3 & CNRM-CM6-1 & 3 & 5 & 3 & 3 \\
\hline 4 & IPSL-CM6A-LR & 3 & 4 & 2 & 3 \\
\hline 5 & MIROC6 & 5 & 6 & 1 & 1 \\
\hline 6 & HadGEM3-GC31-LL & 4 & 3 & 5 & 5 \\
\hline 7 & MRI-ESM2-0 & 2 & 2 & 3 & 2 \\
\hline \multirow[t]{2}{*}{8} & GISS-E2-1-G & 2 & 4 & 3 & 3 \\
\hline & Sum & 33 & 37 & 26 & 26 \\
\hline
\end{tabular}

(a) HCEFI

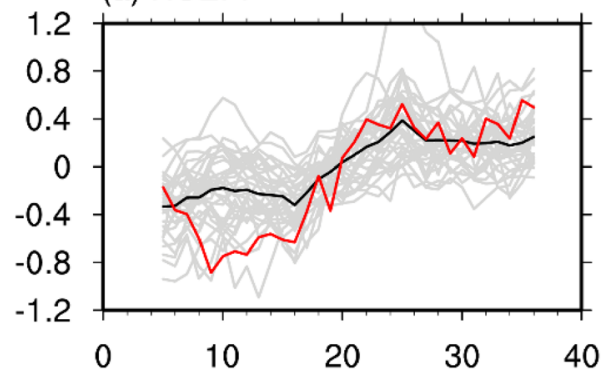

(c) HCEFI

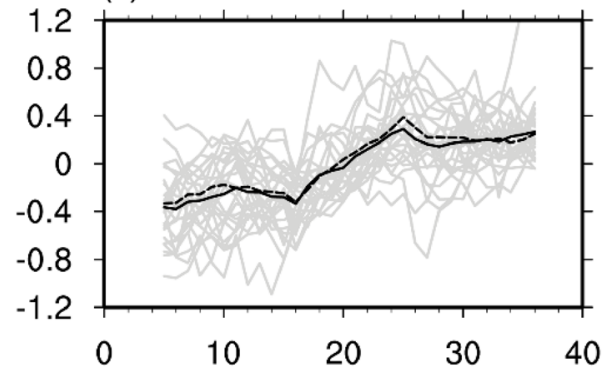

(b) LCEFI

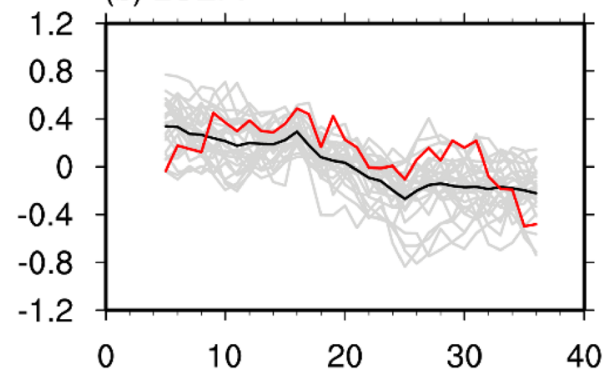

(d) LCEFI

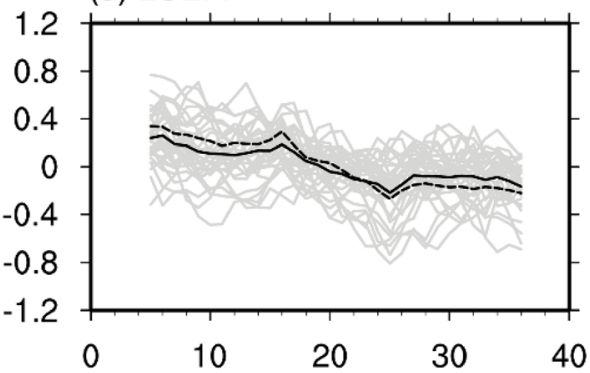


time evolutions of two indices based on the reanalysis are also plotted. Time evolutions of both HCEFI and LCEFI depicted by MCE means show similar features as those based on reanalysis. HCEFI evolutions are characterized by increases (HCEF weakens) during the 40 years and LCEFI by decreases (Fig. 7a, b). The change of HCEFI between two 20 years (last 20 years minus first 20 years) in MCE mean is $0.6 \mathrm{~m} \mathrm{~s}^{-1}$, which accounts for more than $70 \%$ of that based on the reanalysis $\left(0.83 \mathrm{~m} \mathrm{~s}^{-1}\right)$. The change of LCEFI between two 20 years in MCE mean is $-0.55 \mathrm{~m} \mathrm{~s}^{-1}$, being very close to change of $-0.43 \mathrm{~m} \mathrm{~s}^{-1}$ based on the reanalysis. These results indicate similar magnitudes of internal interdecadal variations of CEF in piControl simulations as those in observations.

In addition, in order to examine the consistency between the interdecadal change of HCEF and LCEF in piControl simulations, time evolutions of HCEFI based on 26 weakening cases identified according to LCEF are shown in Fig. 7c. It can be found that time evolutions of HCEF based on LCEFI show high similarity to the time evolutions of that based on HCEFI, especially for MCE mean evolutions.
Meanwhile, cases based on HCEF can also well capture the interdecadal change of LCEF (Fig. 7d). These results indicate that selected cases and their time evolutions are not sensitive to whether HCEFI or LCEFI is used for case selection. Therefore, only corresponding changes in other variables and physical processes for selected cases based on LCEFI are investigated further in the following section.

Spatial patterns of changes for some variables between two 20-year periods of interdecadal weakening cases selected in piControl simulations according to LCEFI are illustrated in Fig. 8. The main features associated with the weakening of CEF are southerly anomalies in the upper troposphere and northerly anomalies in the lower troposphere over the tropical Indo-Pacific region, centered over MC (Fig. 8a, b). The anomalous low-level northerlies are consistent with SLP changes that show a dipole pattern over the western tropical Pacific with positive anomalies to the north of Equator and negative anomalies to the south (Fig. 8d). Associated with these wind anomalies are significant divergence anomalies over MC and adjacent regions in the upper troposphere and convergence anomalies in the
Fig. 8 Spatial patterns of changes between two 20 years in MCE mean of weakening cases selected in piControl simulations according to LCEFI. a Wind fields $\left(\mathrm{m} \mathrm{s}^{-1}\right)$ at $200 \mathrm{hPa}, \mathbf{b}$ at $925 \mathrm{hPa}$, c precipitation $\left(\mathrm{mm} \mathrm{day}^{-1}\right)$, d SLP $(\mathrm{hPa})$, and e SST $\left({ }^{\circ} \mathrm{C}\right.$, the global mean of SST is not subtracted). The Student's $t$ test is applied on $\mathrm{u}$ or $\mathrm{v}$ winds in $(\mathbf{a}, \mathbf{b})$. Consistency among cases are also considered, regions are dotted only if two conditions are both satisfied, i.e. changes are significant at the $95 \%$ confidence level and consistency is over $60 \%$. Dots are larger in regions where consistency exceeds $90 \%$. The regions framed by rectangles in (c) are used to define the precipitation indexes (a) uv200
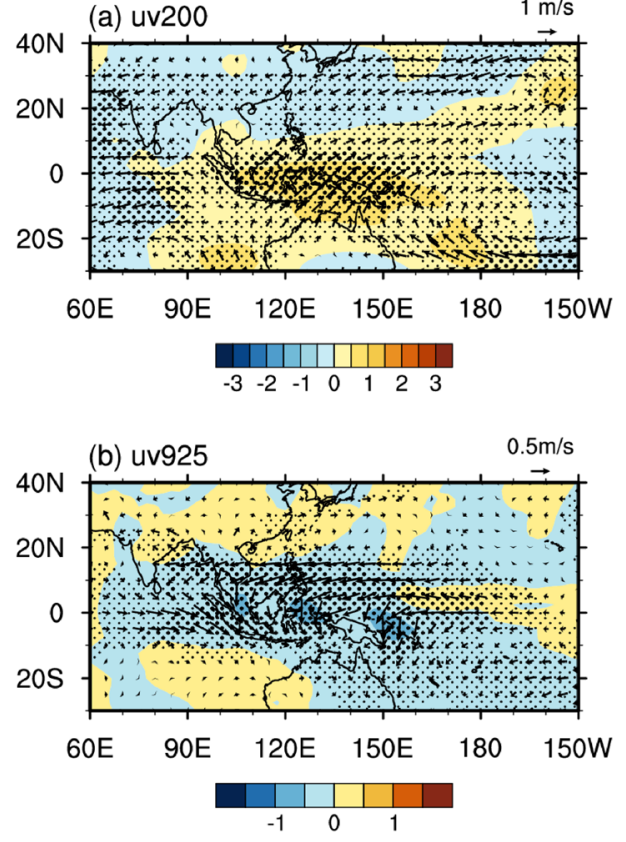

(c) Precip

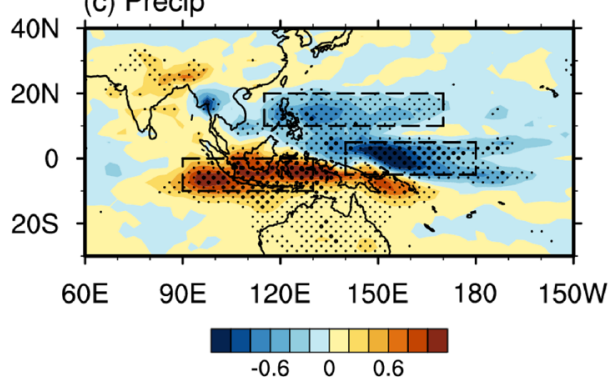

(d) SLP

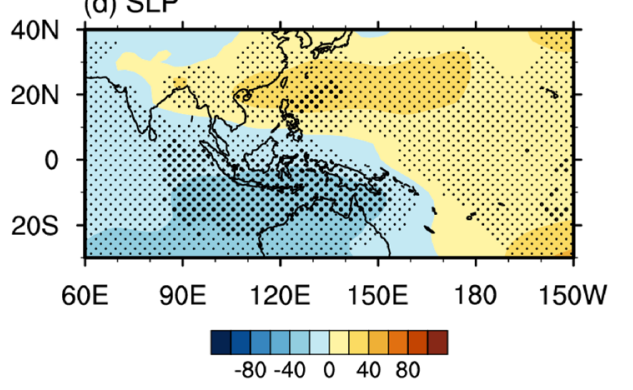

(e) SST

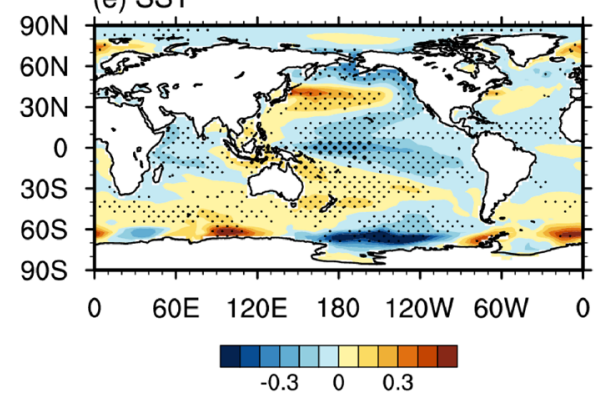


lower troposphere. While changes over WNP are anomalous cyclonic circulation in the upper level and anticyclonic circulation in the lower level. Circulation anomalies over WNP show weaker magnitudes than those over MC. It is worth noted that majority of cases show similar features of large scale circulation changes as demonstrated in those MCE mean, which suggests the robust relationship between the weakening of HCEF and the anomalous circulations over the western tropical Pacific in both the upper and lower troposphere. Associated with the circulation anomalies are strong meridional and zonal seesaw patterns of precipitation with increases over MC and decreases over the central-western Pacific (CWP) and subtropical WNP. Among these changes, the highest multi-cases consistency appears over $\mathrm{MC}$ and CWP (over 90\%), while that over WNP is over $70 \%$. These results suggest that the weakening of CEF is related to both tropical and subtropical convection anomalies, especially the tropical ones. Anomalous circulation and precipitation indicate a change in both the Walker and local Hadley circulation, accounting for the enhanced convection over MC, anomalous southerlies in the upper troposphere (HCEF weakens), reduced convection over subtropical WNP, and anomalous northerlies in the lower troposphere (LCEF weakens). Associated with these large scale changes in circulation and precipitation are anomalous SSTs that show a typical negative IPO pattern, with the cold SST anomalies over the Indian Ocean (IO), central Pacific, and warm SST anomalies around MC and WNP (Fig. 8e). The highest consistency among cases appears over the central tropical Pacific (CTP) (Fig. 8e), which indicates the robustness of the relationship between the interdecadal change of CEF and SST in CTP. In many aspects, the changes in large scale circulation, precipitation, and SST seen in MCE mean selected in piControl simulations (Fig. 8) bear a similarity to main features shown in observations and reanalysis (Fig. 2).

To further demonstrate the relationship between $\mathrm{CEF}$ and IPO, the cross-correlation coefficients between LCEFI and IPO index based on the 500-year piControl simulations in each model are calculated and results are shown in Fig. 9. As shown in Fig. 9, simultaneous correlation shows a maximum in each model, and it passes the $95 \%$ significant test. This implies that from the aspect of internal variability, IPO undergoes a synchronous phase transition along with the interdecadal change of LCEF. Besides, the ensemble mean of the SST anomalies regressed onto the IPO index (Fig. S2) based on piControl simulations show high similarity with Fig. 8e and it verifies again that the SST anomalies associated the weakening of CEF is negative phase of IPOlike pattern.

The above analyses indicate that associated with the interdecadal weakening of CEF is anomalous precipitation over three regions of MC, WNP and CWP (Fig. 8c). What are circulation and SST anomalies associated with anomalous precipitation in these three key regions? Three precipitation indices are defined, i.e. $10^{\circ} \mathrm{S}-\mathrm{eq}, 90-130^{\circ} \mathrm{E}$ for MCI, $5^{\circ} \mathrm{S}-5^{\circ} \mathrm{N}, 140^{\circ} \mathrm{E}-180$ for CWPI, and $10-20^{\circ} \mathrm{N}$, $115-170^{\circ} \mathrm{E}$ for WNPI. For easy comparison, CWPI and WNPI are changed the sign (multiplied by -1 ) before performing regression analyses. Nine-year running average is applied to retain the interdecadal component. Figure 10 represents the ensemble means of regression maps and it shows that the wind anomalies associated with MCI (Fig. 10a and b) mainly explain the tropical part of circulation changes shown in Fig. 8a and b, characterized by strong divergence (convergence) over $\mathrm{MC}$ in the upper (lower) troposphere. For CWPI (Fig. $10 \mathrm{~d}$ and e), due to the relationship with MCI ( -0.45 , same sign for all models), regression patterns show similar structures as those associated with MCI, characterized by anomalous upper level divergence (lower level convergence) over MC. Besides, the CWPI-related wind anomalies exist symmetrically about the equator, which is ineffective to the interdecadal change of CEF. By contrast, WNPI-related circulation anomalies (Fig. 10g and h) mainly dominate over the subtropical WNP, featured by an anomalous cyclonic circulation at $200 \mathrm{hPa}$ and anticyclonic circulation at $925 \mathrm{hPa}$, which mainly explain the subtropical part of circulation changes shown in Fig. 8. The correlation coefficient between MCI and WNPI is -0.44 with all models showing same sign, which suggests a close relationship between convections in these two regions. In contrast, the correlation between CWPI and WNPI is 0.07, with half models showing opposite sign, which indicates an uncertainty in relationship between convection variations between CWP and WNP. The corresponding SST changes associated
Fig. 9 The cross-correlation coefficient between 9-year running averaged LCEFI and IPO index based on the 500-year piControl simulations in each model. $\mathrm{X}$-axis is years and positive value means that IPO leads LCEFI, and vice versa. Dashed lines represent the 0.05 significance level
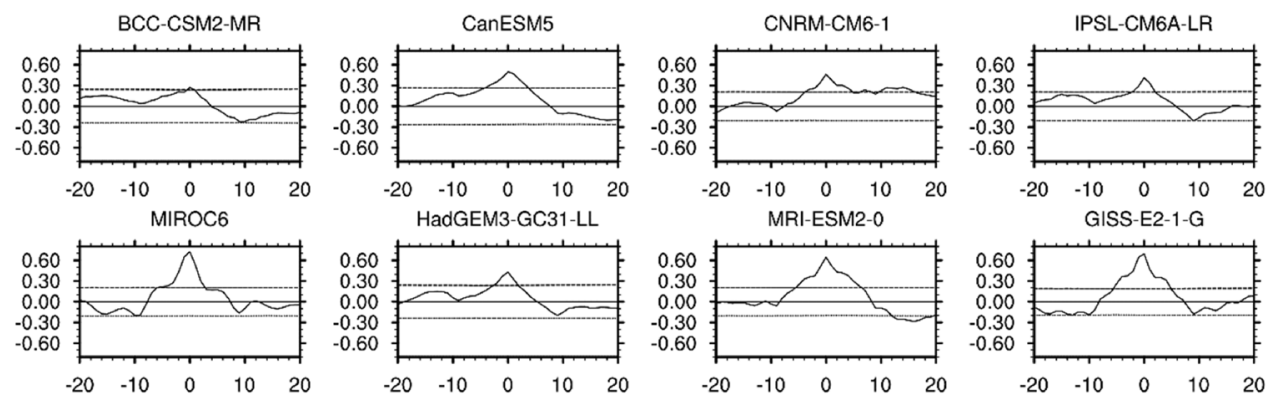
Fig. 10 MME mean of the regression maps for $\mathbf{a}$ wind fields $\left(\mathrm{m} \mathrm{s}^{-1}\right.$; uv: vector; v: shading) at $200 \mathrm{hPa}, \mathbf{b} 925 \mathrm{hPa}$, c SST $\left({ }^{\circ} \mathrm{C}\right)$ on MCI based on the 500-year piControl simulations in each model. 9-year running average is applied first. Consistency among each model is considered, Dots represent regions where the consistency is over $60 \%$. Dots are larger for regions where consistency exceeds $90 \%$. $\mathbf{d}-\mathbf{f}$ and $\mathbf{g}-\mathbf{i}$ are same as (a-c), but for CWPI and WNPI, respectively. Note MCI, CWPI and WNPI are standardized, and CWPI and WNPI are multiplied by -1 for easy comparison
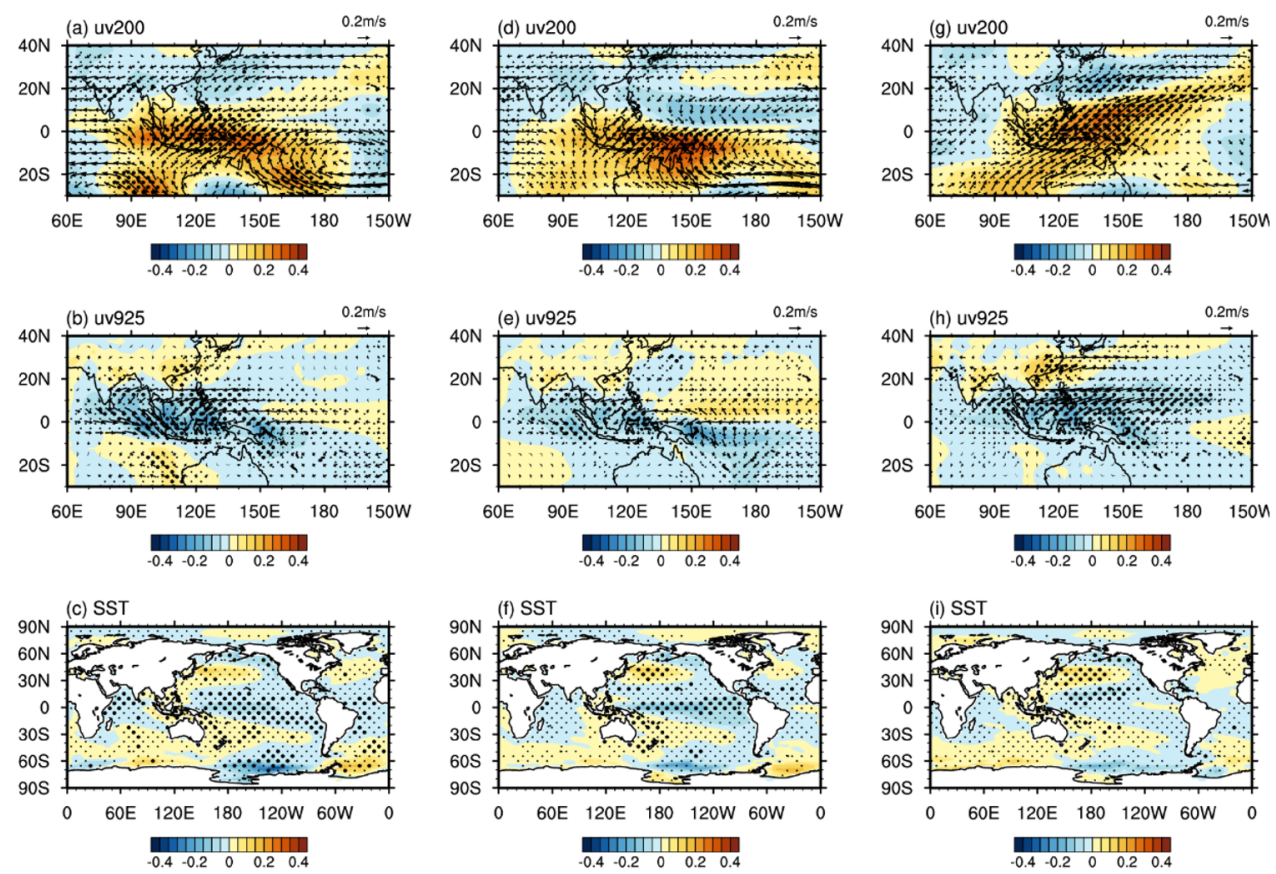

CEF are associated with positive IPO phases in piControl simulations and further support our conclusions that IPO phase changes are important for phases changes of CEF on the interdecadal time scale (Fig. 11).

Additionally, 37 (26) interdecadal strengthening cases based on HCEFI (LCEFI) are identified in piControl simulations and the details of these cases are also shown in Table 2. Time evolutions of HCEFI and LCEFI are given in Fig. 11. The high similarity of time evolutions between red and black line indicates that the interdecadal strengthening of HCEF and LCEFI identified by the piControl simulation are strongly consistent. Changes in horizontal circulation, precipitation, SLP and SST associated with the strengthening of CEF are also analyzed (Fig. S3) and they show similar features to those for weakening cases with a change in sign. These results demonstrate that interdecadal strengthening of

(a) HCEFI

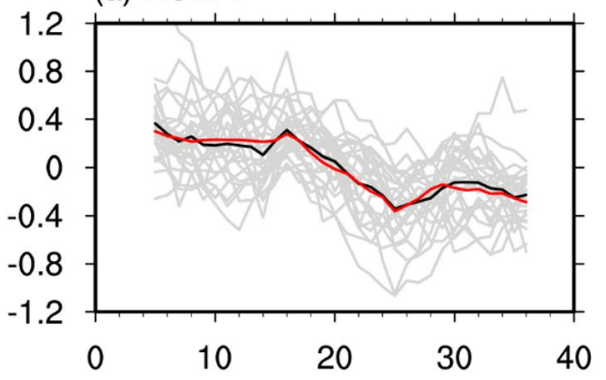

Fig. 11 Time evolutions of interdecadal strengthening cases (unit: $\mathrm{m} \mathrm{s}^{-1}$ ) selected from the 8 piControl simulations in CMIP6 models. a 9-year running average of HCEFI depicted by strengthening cases according to LCEFI (grey lines) and their multi case ensemble (MCE) mean (black line). The red line represents the MCE mean of

\section{Sensitivity experiments and further understanding the interdecadal weakening of CEF}

As demonstrated in the previous sections, SST changes associated with the interdecadal weakening of CEF in piControl simulations show a negative IPO pattern. To better understand the mechanisms that how IPO acts on CEF, and the relative roles of SST anomalies in different regions, some

\section{(b) LCEFI}

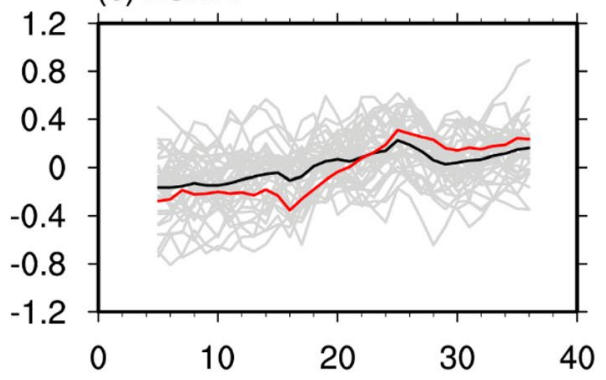

HCEFI depicted by strengthening cases according to HCEFI. b 9-year running average of LCEFI depicted by strengthening cases according to HCEFI (grey lines) and their MCE mean (black line). The red line represents the MCE of LCEFI depicted by strengthening cases according to LCEFI 
numerical experiments are carried out by using the latest Met Office atmosphere and land model GA6.0 (MetUMGA6). First, a control experiment is forced by the monthly mean global SSTs averaged for the first 20 years of the weakening cases ensemble mean in CMIP6 piControl simulations selected according to LCEFI. Then six sensitivity experiments (shown in Table 3) are performed for global, Indian Ocean (IO), western North Pacific (WNP), Maritime Continent (MC), central tropical Pacific (CTP), and subtropical northern Pacific (SNP), with SST anomalies between the second 20-year mean and first 20-year mean added to the SSTs in the control, respectively. These key regions are selected based on spatial pattern of changes in SSTs (Fig. 8e) and the precipitation-related SST anomalies in regression patterns (Fig. 10) associated with the interdecadal weakening of CEF. All experiments are integrated for 42 years, and the JJA mean in last 40 years is analyzed. Differences between sensitivity experiments and the control experiment represent the respective influence of SST changes in corresponding regions.

The changes of HCEFI and LCEFI between each sensitivity experiment and the control experiment are summarized in Fig. 12. With global SST changes associated with negative IPO pattern, EXP1 reproduces changes of both HCEFI and LCEFI simulated in the piControl simulations, confirming that the phase transition of IPO can lead to the interdecadal change of CEF. For relative roles of SST anomalies in different regions, those over CTP play a dominant role with further contribution from SST changes over MC, while SST anomalies over WNP play an opposite role. In the coupled model simulations (Fig. 8) and in observations (Fig. 2), the positive SST anomalies over WNP are associated with reduced precipitation, suggesting that SST changes are a result of reduced cloud cover due to reduced convection. However, the warm SST anomalies lead to enhanced convection when they are imposed in an atmospheric general circulation model (AGCM). Thus, local relationships between SST and convection over WNP in uncoupled atmospheric model simulation are opposite to those in coupled model

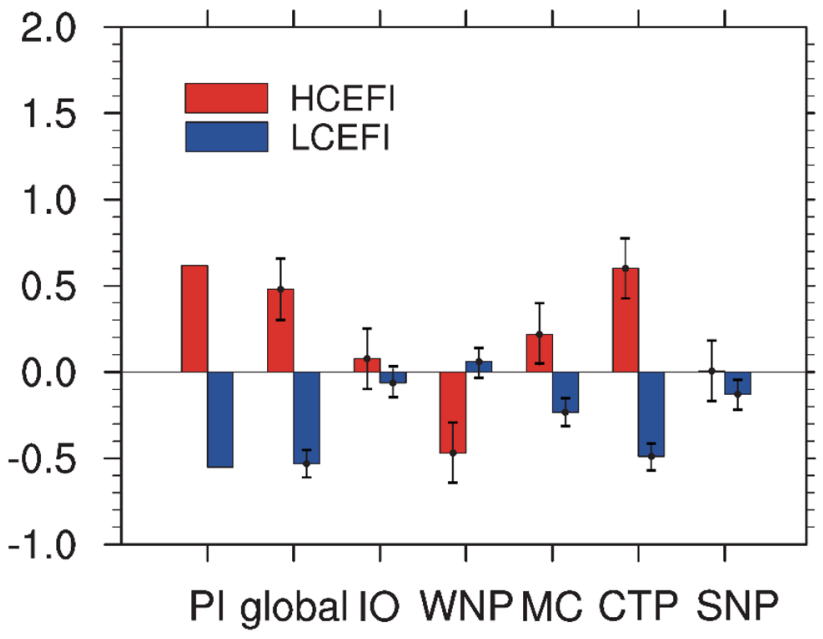

Fig. 12 Interdecadal change of HCEFI (red bars) and LCEFI (blue bars) between two subperiods in MCE of weakening cases in piControl simulations (PI) selected according to LCEFI, and the changes forced by SST anomalies in global, IO, WNP, MC,CTP and SNP. The error bar represents the standard error due to the internal variability of atmosphere based on the Control experiment

simulation (e.g., Wang et al. 2005; Dong et al. 2017), and therefore are associated with opposite changes in CEF. The influences of IO and SNP are relatively weak (Fig. 12).

Responses of circulation and some other variables to the global SST changes are shown in Fig. 13. Changes of circulation are significant southerly anomalies at $200 \mathrm{hPa}$ and significant northerly anomalies at $925 \mathrm{hPa}$ over the western and central tropical Pacific (Fig. 13a, b), indicating the weakening of both HCEF and LCEF. Associated with these changes in CEF are anomalous low SLP, ascent, and increased precipitation over MC and anomalous high SLP, decent, and decreased precipitation over WNP (Fig. 13d, c, f), indicating a local Hadley circulation change over the western Pacific sector. The precipitation responses also show strong west-east dipole pattern, with positive anomalies over $\mathrm{MC}$ and negative anomalies over CWP (Fig. 13c). This zonal diploe pattern of precipitation changes is associated with
Table 3 Summary of numerical experiments

\begin{tabular}{ll}
\hline Experiment & Boundary condition \\
\hline Control & Global SST from former subperiod (P1) MCE of the weakening cases \\
EXP1 & Global SST from latter subperiod (P2) MCE of the weakening cases \\
EXP2 & $\mathrm{IO}\left(15^{\circ} \mathrm{S}-15^{\circ} \mathrm{N}, 40-80^{\circ} \mathrm{E}\right)$ from $\mathrm{P} 2+$ rest ocean from P1 \\
EXP3 & $\mathrm{WNP}\left(\mathrm{eq}-20^{\circ} \mathrm{N}, 100-140^{\circ} \mathrm{E}\right)$ from $\mathrm{P} 2+$ rest ocean from $\mathrm{P} 1$ \\
EXP4 & $\mathrm{MC}\left(15^{\circ} \mathrm{S}-\mathrm{eq}, 100-150^{\circ} \mathrm{E}\right)$ from $\mathrm{P} 2+$ rest ocean from P1 \\
EXP5 & $\mathrm{CTP}\left(10^{\circ} \mathrm{S}-10^{\circ} \mathrm{N}, 160^{\circ} \mathrm{E}-120^{\circ} \mathrm{W}\right)$ from P2 + rest ocean from P1 \\
EXP6 & $\mathrm{SNP}\left(10-20^{\circ} \mathrm{N}, 160^{\circ} \mathrm{E}-120^{\circ} \mathrm{W}\right)$ from $\mathrm{P} 2+$ rest ocean from $\mathrm{P} 1$ \\
\hline
\end{tabular}

GHG, aerosols, and sea ice extent are the same in all experiments and they are taken as mean values averaged over the period 1994-2011 (e.g., Dong et al 2019). P1 is the first 20 year mean and P2 is the second 20 year mean of interdecadal weakening MCE 
Fig. 13 Responses for a wind fields ( $\mathrm{m} \mathrm{s}^{-1}$; uv: vector; v: shading) at $200 \mathrm{hPa}, \mathbf{b} 925 \mathrm{hPa}$, c precipitation $\left(\mathrm{mm} \mathrm{day}^{-1}\right), \mathbf{d}$ SLP (hPa), e pressure-longitude cross section of vertical and zonal winds averaged over $5^{\circ} \mathrm{S}-5^{\circ} \mathrm{N}\left(\mathrm{m} \mathrm{s}^{-1}\right.$; uw: vector; $\mathrm{w}$ : shading), and $\mathbf{f}$ pressurelatitude cross section of vertical and meridional winds ( $\mathrm{m}$ $\mathrm{s}^{-1}$; vw: vector; w: shading) averaged over $100-140^{\circ} \mathrm{E}(\mathrm{m}$ $\mathrm{s}^{-1}$; vw: vector; w: shading) in JJA to the global SST anomalies (EXP1 minus Control). Vertical winds are multiplied by 100 , positive values represent ascending movements. The Student's $t$ test is applied on $\mathrm{u}$ or $\mathrm{v}$ winds in $(\mathbf{a}, \mathbf{b})$, $\mathrm{u}$ or $\mathrm{w}$ winds in (e), $\mathrm{v}$ or $\mathrm{w}$ winds in (f). Dots represent regions where responses are significant at the 90\% confidence level
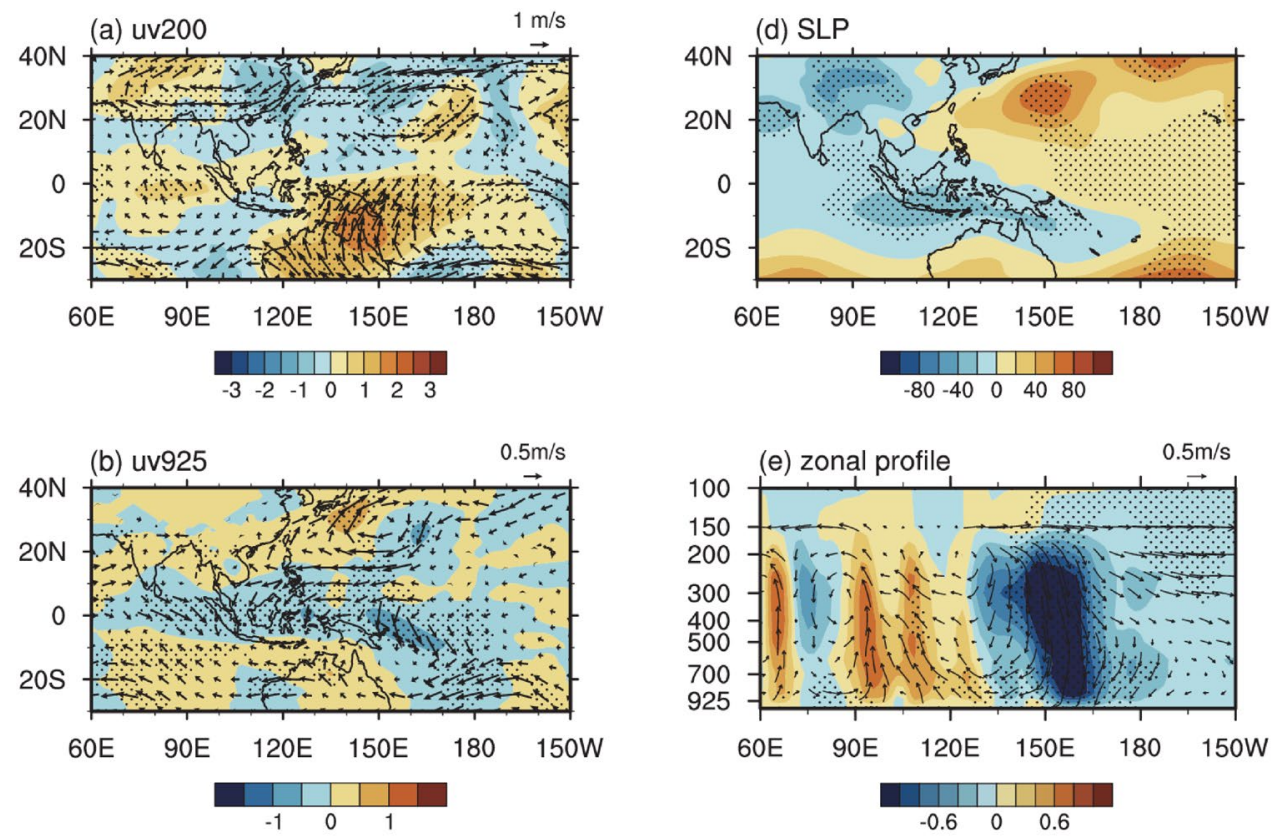

(c) Precip

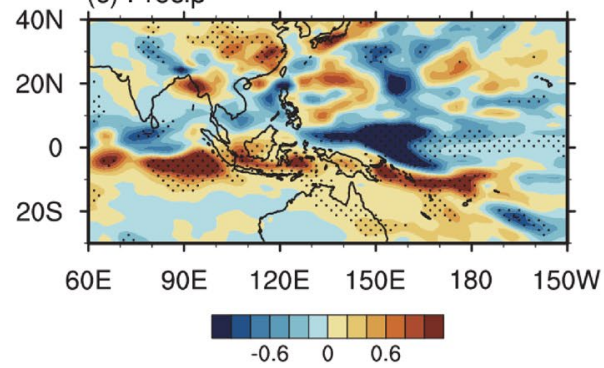

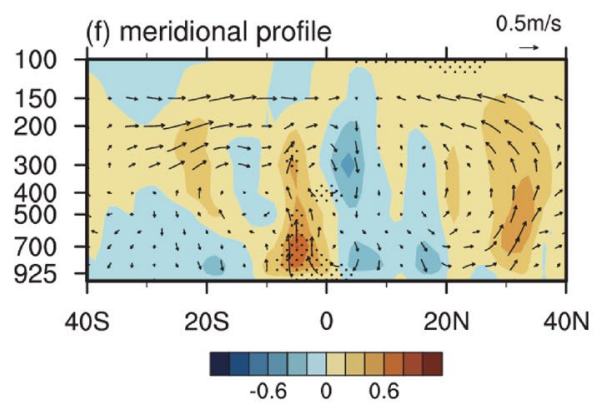

anomalous ascents over MC and anomalous descents over CWP (Fig. 13e), indicating an enhancement of the Walker circulation. These features of circulation and precipitation changes are similar to those shown in Fig. 8, indicating that atmospheric model responses to global SST changes basically reproduce many features of circulation and precipitation changes associated with the interdecadal weakening CEF cases identified in piControl simulations. This similarity indicates that it is proper to use this AGCM to investigate and quantify relative roles of SST anomalies in different regions on the interdecadal weakening of CEF.

Responses of circulation and some other variables to SST anomalies over CTP are illustrated in Fig. 14. Strong southerly (northerly) wind responses at $200 \mathrm{hPa}(925 \mathrm{hPa})$ exist over MC (Fig. 14a and b), which indicate the weakening of HCEF (LCEF). The associated circulation anomalies show some contrasting features between MC and WNP, characterized by anomalous divergence (convergence) over $\mathrm{MC}$ and anomalous cyclonic (anticyclonic) circulation over WNP in the upper (lower) troposphere. SLP anomalies (Fig. 14d) show a meridional dipole pattern with positive anomalies to the north of MC and negative anomalies to the south, being consistent with anomalous northerlies in the lower troposphere. Zonal circulation changes averaged over $5^{\circ} \mathrm{S}-5^{\circ} \mathrm{N}$ show anomalous descending motions centered over CWP and anomalous ascending motions in large regions to the west of $150^{\circ} \mathrm{E}$ with anomalous easterlies in the lower troposphere and anomalous westerlies in the upper troposphere, suggesting an enhancement of the Walker circulation (Fig. 14e). SST changes in CTP also lead to changes in the Hadley circulation and convection over the western Pacific sector, characterized by anomalous ascents, enhanced convection over MC and anomalous descents, reduced convection over WNP (Fig. 14c, f). This process has been well documented in some previous works (Lu and Dong 2001; Sui et al. 2007; Chung et al. 2011). In addition, the cold SST anomaly over CTP can also influence the low-level subtropical anticyclonic circulation over WNP by Rossby wave (Wang et al. 2013; Xiang et al. 2013; Chen et al. 2015). Many aspects of circulation and precipitation changes in CTP experiment are similar to those seen in global SST experiments, suggesting a dominant role of cold SST anomalies in CTP for the weakening of CEF associated with negative phase of IPO pattern (Fig. 12). 
Fig. 14 Same as Fig. 13, but for responses to SST anomalies in CTP (EXP5 minus Control)
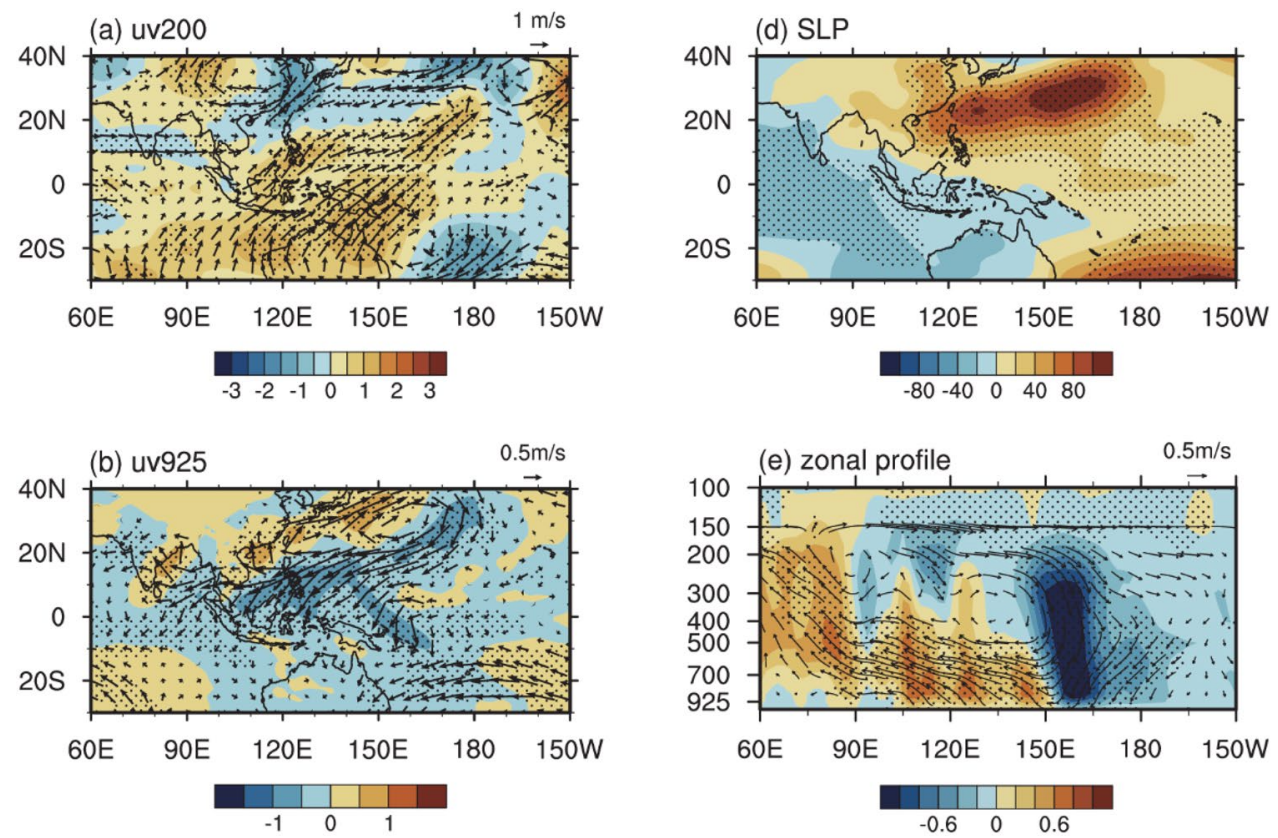

(c) Precip

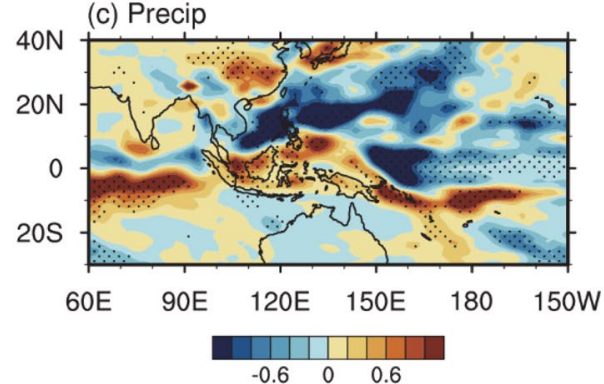

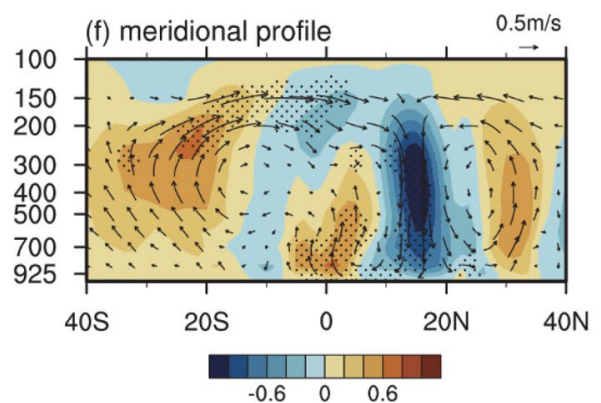

Responses of circulation and some other variables to SST anomalies over MC are illustrated in Fig. 15. In response to warm SST changes in MC, the significant equatorial meridional wind responses concentrate to the west of $130^{\circ} \mathrm{E}$ (Fig. 15a, b), which can only explain the part of changes of CEF seen in global experiment (Fig. 13a and b). The anomalous cyclonic (anticyclonic) circulations in subtropics, and the associated precipitation anomalies (Fig. 15c) over MC and WNP are basically captured, but with weak magnitudes compared to those stimulated by either global SST change or CTP SST change (Figs. 13, 14). The weak precipitation changes and CEF changes are consistent with SLP anomalies that show in a weak meridional gradient (Fig. 15d). In addition, warm SST anomalies over MC do not lead to significant changes in zonal circulation over equator although they lead to changes in the local Hadley circulation over the western Pacific sector with weak magnitudes. In summary, the local SST changes over MC can lead to the interdecadal change of $\mathrm{CEF}$, but the effects are relatively weak compared with those in responses to CTP SST change.

Warm SST anomalies over WNP lead to a strengthening of CEF, especially having large influence on HCEF
(Fig. 12), which tend to damp the responses to SST changes over either CTP or MC. Processes involved are warm SST over WNP lead to enhanced convection locally, that induces anomalous southerlies in the lower troposphere in the western tropical Pacific (Fig. S4). These changes are opposite to the responses to SST anomalies over either CTP or MC. Besides, the influences of SST changes over IO and SNP are relatively weak (Fig. 12), and spatial patterns of changes in circulation and precipitation are also weak (Figs. S5, S6).

\section{Conclusions and discussions}

In this study, the observed interdecadal changes of crossequatorial flows (CEF) around the Maritime Continent (MC) in boreal summer across the mid-1990s between two periods 1995-2014 (P2) and 1975-1994 (P1) have been investigated. The outputs of eight coupled models in CMIP6, including historical all forcing simulations, single forcing simulations due to changes in anthropogenic aerosol (AA), Greenhouse gases (GHG) and natural (NAT) forcings, pre-industrial control (piControl) simulations, and a set of atmospheric general 
Fig. 15 Same as Fig. 13, but for responses to SST anomalies in MC (EXP4 minus Control)
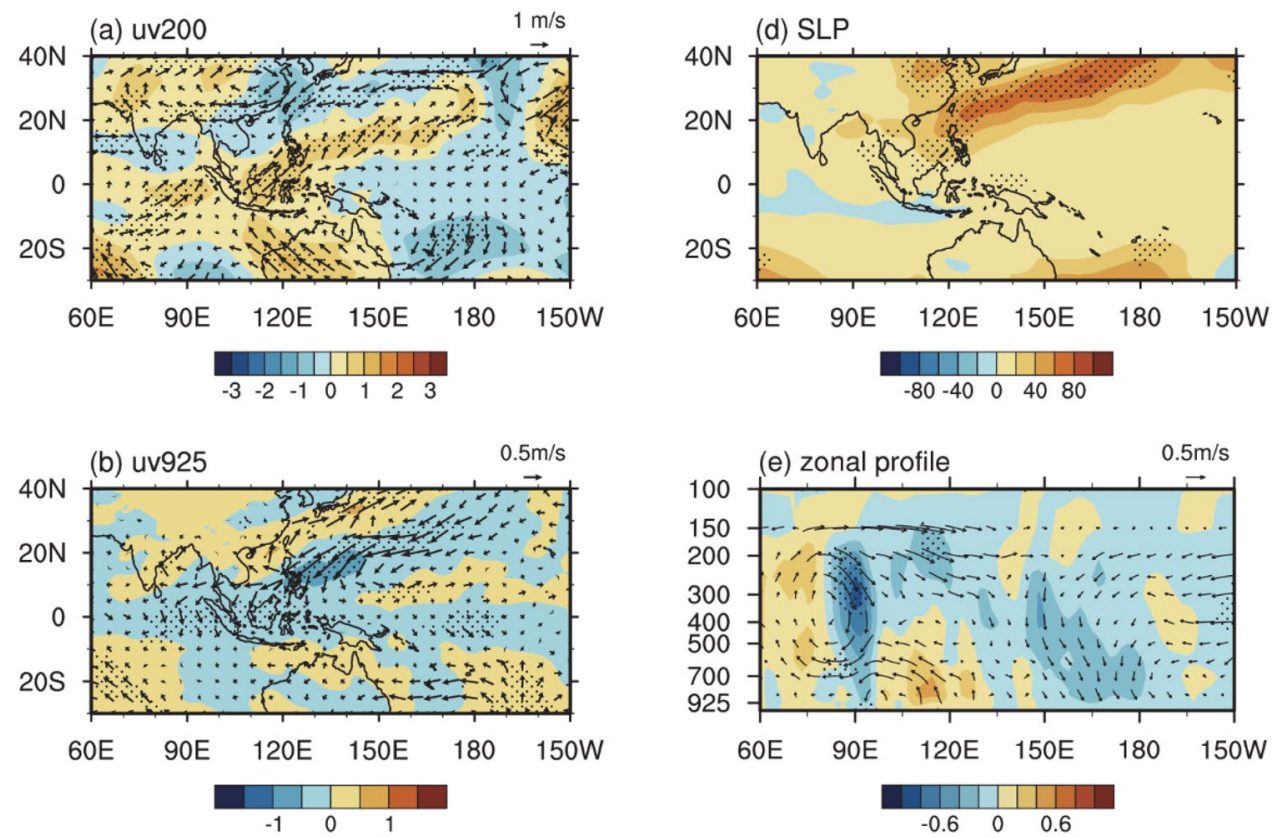

(c) Precip

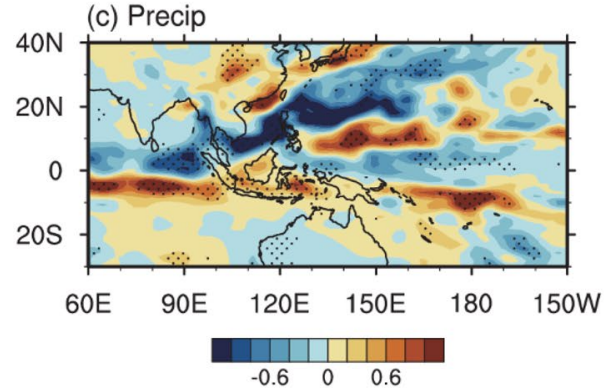

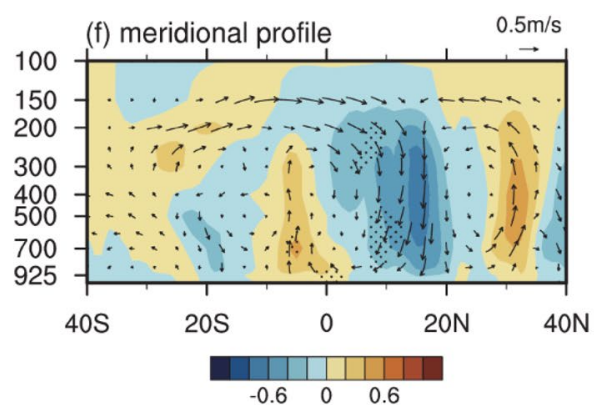

circulation model experiments, are used to investigate drivers and to assess the respective roles of external forcing and internal variability, and to understand physical mechanisms. The main findings are summarized as follows:

- JRA55 and NCEP reanalyses show that the CEF at both upper and lower troposphere in boreal summer underwent a significant interdecadal weakening during 19752014, characterized by weakening of upper tropospheric northerlies and lower tropospheric southerlies within the western tropical Pacific. This change of CEF is associated with anomalous local Hadley circulation and the enhanced Walker circulation. Corresponding changes in SSTs bear a similarity to negative phase of the interdecadal Pacific Oscillation (IPO), suggesting that phase transition of IPO might be responsible for the interdecadal weakening of CEF during the last 40 years in observations.

- The change of CEF in the multi-model ensemble mean of historical simulations in eight CMIP6 models forced by all-forcing (ALL) and anthropogenic aerosol (AA), greenhouse gases (GHG) and natural forcing (NAT) can only explain a small fraction of that change in observations, indicates the weak response to the external forcings. By contrast, the interdecadal changes in each member of eight CMIP6 models show large spread, suggesting the strong internal variability.

- To illustrate the role of internal variability, 33 (26) weakening cases for HCEFI (LCEFI) are selected from the 500-year piControl simulations. Changes of CEF simulated by the multi-case ensemble show similar characteristics as those in observations (reanalyses) in many aspects. The weakening of CEF is associated with the in-phase transition of IPO to negative phase.

- Numerical experiments based on MetUM-GA6 are carried out to assess relative roles of SST anomalies in different regions associated with negative IPO identified in internal interdecadal weakening cases of CEF. Results show that the negative IPO-like global SST changes lead to the weakening of CEF in both upper and lower troposphere. Among different regions, CTP plays a dominant role. The cold SST anomalies in CTP lead to reduced convection over CWP, which induces an anomalous Walker circulation with enhanced convection over MC. 
The enhanced convection over MC further induces the rainfall anomalies over WNP through changes in local Hadley circulation, leading to weakening of CEF in both upper and lower troposphere. Meanwhile, the warm SST anomalies over MC force a local Hadley circulation change in the western tropical Pacific with enhanced convection over $\mathrm{MC}$ and reduced convection WNP, leading to weakening of CEF but with weak changes than those in response to cold SST anomalies in the CTP.

Positive Atlantic Multidecadal Osillation (AMO)-like SST anomalies can also be found in observations (Fig. 2f) with the positive AMO pattern, consistent with previous works (Dong et al. 2006; Kucharski et al. 2016; Gong et al. 2020) which pointed out the AMO underwent a transition from negative to positive phase in around mid-1990s. These works further suggested that the Atlantic warming from the mid-1990s might have triggered IPO phase change around the mid-1990s in the Pacific (e.g., Dong et al. 2006; Kucharski et al. 2016), highlighting the influence of the Atlantic. The possible teleconnection of SST anomalies between the North Atlantic and Pacific Ocean associated with internal variability in model piControl simulations is also evident in Fig. S2. Besides, to illustrate the possible linkage between CEF and AMO, we define an AMO index following Enfield et al. (2001) and calculate the cross-correlation coefficient between CEF and AMO based on piControl simulations. Correlations in different models show strong uncertainty with the simultaneous positive correlation being significant in only few models (figure not shown). Partial correlation between CEF and AMO under the constraint that IPO is held constant is further analyzed for those "close relationship" models, and results show that the linkage between CEF and AMO depends on the influence of IPO. Thus, we tend to conclude that the relationship between CEF and AMO is not robust, this can also be implied by Fig. 8e, in which the SST anomalies associated with the weakening of CEF over the North Atlantic are weak and not significant.

In this study, the interdecadal changes of CEF in observations, drivers and physical processes have been investigated using CMIP6 climate model simulations and a set of AGCM sensitivity experiments. Many aspects of changes in circulation, precipitation, and SST associated with internal interdecadal variability in both their spatial patterns and magnitudes bear a similarity to those in observations (reanalysis) across the mid-1990s. This similarity between observed changes and those associated with internal interdecadal variability, together with weak multimodel mean responses to external forcing, suggests that interdecadal weakening of CEF in observations during the last four decades is likely be an internal interdecadal variability. However, there are still some remaining questions. How interdecadal changes of CEF affect climate over East Asia or over regions across the western tropical Pacific? Especially how interdecadal changes of CEF affect extreme climate events over East Asia and adjacent regions? Besides, our analyses show a crucial role of IPO on interdecadal variations of CEF, what is the mechanism of IPO in CMIP6 model simulations? These are important questions that need to be investigated.

Supplementary Information The online version contains supplementary material available at https://doi.org/10.1007/s00382-021-05692-1.

Acknowledgements This research is completed during the abroad visiting study of Xiaoxuan Zhao, which is funded under the State Scholarship Fund. BD is supported by the UK National Centre for Atmospheric Science at the University of Reading. This research was supported by the National Natural Science Foundation of China (Grant Nos. 41875072 and 41721004). Use of the UK NERC (Natural Environment Research Council) CEDA-JASMIN facility is acknowledged for data storage and analysis. We like to thank three anonymous reviewers for their constructive comments and suggestions that help to improve this paper.

Open Access This article is licensed under a Creative Commons Attribution 4.0 International License, which permits use, sharing, adaptation, distribution and reproduction in any medium or format, as long as you give appropriate credit to the original author(s) and the source, provide a link to the Creative Commons licence, and indicate if changes were made. The images or other third party material in this article are included in the article's Creative Commons licence, unless indicated otherwise in a credit line to the material. If material is not included in the article's Creative Commons licence and your intended use is not permitted by statutory regulation or exceeds the permitted use, you will need to obtain permission directly from the copyright holder. To view a copy of this licence, visit http://creativecommons.org/licenses/by/4.0/.

\section{References}

Bretherton CS, Widmann M, Dymnikov VP, Wallace JM, Bladé I (1999) The effective number of spatial degrees of freedom of a time-varying field. J Clim 12:1990-2009

Chen M, Xie P, Janowiak JE, Arkin PA (2002) Global land precipitation: a 50-year monthly analysis based on gauge observations. J Hydrometeorol 3:249-266

Chen Z, Wen Z, Wu R, Lin X, Wang J (2015) Relative importance of tropical SST anomalies in maintaining the western North Pacific anomalous anticyclone during El Niño to La Niña transition years. Clim Dyn 46:1027-1041. https://doi.org/10.1007/s0038 2-015-2630-1

Cheng Y, Wang L, Li T (2020) Causes of interdecadal increase in the intraseasonal rainfall variability over southern China around the early 1990s. J Clim 33:9481-9496. https://doi.org/10.1175/ JCLI-D-20-0047.1

Chung P-H, Sui C-H, Li T (2011) Interannual relationships between the tropical sea surface temperature and summertime subtropical anticyclone over the western North Pacific. J Geophys Res. https ://doi.org/10.1029/2010jd015554

Cong J, Guan ZY, Wang LJ (2007) Interannual (interdecadal) variabilities of two cross_equatorial flows in association with the Asian summer monsoon variations. J Nanjing Inst Meteorol 30:779-785 (in Chinese) 
Dai A (2012) The influence of the inter-decadal Pacific oscillation on US precipitation during 1923-2010. Clim Dyn 41:633-646. https ://doi.org/10.1007/s00382-012-1446-5

Dong B, Lu R (2013) Interdecadal enhancement of the Walker circulation over the tropical Pacific in the late 1990s. Adv Atmos Sci 30:247-262. https://doi.org/10.1007/s00376-012-2069-9

Dong B, Sutton RT, Scaife AA (2006) Multidecadal modulation of El Niño-Southern oscillation (ENSO) variance by Atlantic Ocean sea surface temperatures. Geophys Res Lett 33:L08705

Dong B, Sutton RT, Shaffrey L, Klingaman NP (2017) Attribution of forced decadal climate change in coupled and uncoupled oceanatmosphere model experiments. J Clim 30(16):6203-6223

Dong B, Wilcox L, Highwood E, Sutton R (2019) Impacts of recent decadal changes in Asian aerosols on the East Asian summer monsoon: roles of aerosol-radiation and aerosol-cloud interactions. Clim Dyn. https://doi.org/10.1007/s00382-019-04698-0

Enfield DB, Mestas-Nuñez AM, Trimble PJ (2001) The Atlantic multidecadal oscillation and its relation to rainfall and river flows in the continental U.S. Geophys Res Lett 28:2077-2080. https://doi.org/10.1029/2000gl012745

Eyring V, Bony S, Meehl GA, Senior CA, Stevens B, Stouffer RJ, Taylor KE (2016) Overview of the Coupled Model Intercomparison Project Phase 6 (CMIP6) experimental design and organization. Geosci Model Dev 9:1937-1958. https://doi. org/10.5194/gmd-9-1937-2016

Feng T, Shen XY, Huang RH, Chen GH (2017) Influence of the interannual variation of cross-equatorial flow on tropical cyclogenesis over the western North Pacific. J Trop Meteor 23:68-80. https://doi.org/10.16555/j.1006-8775.2017.01.007

Frankcombe LM, England MH, Kajtar JB, Mann ME, Steinman BA (2018) On the choice of ensemble mean for estimating the forced signal in the presence of internal variability. J Clim 31:5681-5693. https://doi.org/10.1175/jcli-d-17-0662.1

Gao H, Xue F (2006) Seasonal variation of the cross-equatorial flows and their influences on the onset of South China Sea summer monsoon. Clim Environ Res 11:57-68 (in Chinese)

Gong Y, Li T, Chen L (2020) Interdecadal modulation of ENSO amplitude by the Atlantic multi-decadal oscillation (AMO). Clim Dyn 55:2689-2702. https://doi.org/10.1007/s00382-02005408-X

Han SY, He JH (2002) The time-space variation characteristics of cross-equatorial air flow and the relation to China summer rainfall and to tropical cyclone frequency in the northwest Pacific (in Chinese). Dissertation, Nanjing Institute of Meteorology

Harada Y et al (2016) The JRA-55 reanalysis: representation of atmospheric circulation and climate variability. J Meteorol Soc Jpn Ser II 94:269-302. https://doi.org/10.2151/jmsj.2016-015

Henley BJ, Gergis J, Karoly DJ, Power S, Kennedy J, Folland CK (2015) A tripole index for the interdecadal Pacific oscillation. Clim Dyn 45:3077-3090. https://doi.org/10.1007/s0038 2-015-2525-1

Hu Z-Z (1997) Interdecadal variability of summer climate over East Asia and its association with $500 \mathrm{hPa}$ height and global sea surface temperature. J Geophys Res Atmos 102:19403-19412. https://doi.org/10.1029/97jd01052

Hua W, Dai A, Qin M (2018) Contributions of internal variability and external forcing to the recent Pacific decadal variations. Geophys Res Lett 45:7084-7092. https://doi.org/10.1029/2018g 1079033

Kalnay E et al (1996) The NCEP/NCAR 40-year reanalysis project. Bull Amer Meteorol Soc 77:437-471

Kobayashi S et al (2015) The JRA-55 reanalysis: general specifications and basic characteristics. J Meteorol Soc Jpn Ser II 93:5-48. https://doi.org/10.2151/jmsj.2015-001

Kravtsov S, Callicutt D (2017) On semi-empirical decomposition of multidecadal climate variability into forced and internally generated components. Int J Climatol 37:4417-4433. https:// doi.org/10.1002/joc.5096

Kucharski F, Ikram F, Molteni F, Farneti R, Kang IS, No HH, King MP, Giuliani G, Mogensen K (2016) Atlantic forcing of pacific decadal variability. Clim Dyn 46(7-8):2337-2351

Lau K-M, Li M-T (1984) The monsoon of East Asia and its global associations-a survey. Bull Am Meteorol Soc 65:114-125

Li C, Li S (2014) Interannual seesaw between the Somali and the Australian cross-equatorial flows and its connection to the East Asian summer monsoon. J Clim 27:3966-3981. https://doi. org/10.1175/jcli-d-13-00288.1

Lin Y-W, Chou C (2014) The role of the New Guinea cross-equatorial flow in the interannual variability of the western North Pacific summer monsoon. Environ Res Lett. https://doi. org/10.1088/1748-9326/9/4/044003

Lin R, Zhu J, Zheng F (2016) Decadal shifts of East Asian summer monsoon in a climate model free of explicit GHGs and aerosols. Sci Rep 6:38546. https://doi.org/10.1038/srep38546

Liu H, Zhou T, Zhu Y, Lin Y (2012) The strengthening East Asia summer monsoon since the early 1990s. Chinese Sci Bull 57:1553-1558. https://doi.org/10.1007/s11434-012-4991-8

Lu R, Dong B (2001) Westward extension of north Pacific subtropical high in summer. J Meteorol Soc Jpn 79:1229-1241. https:// doi.org/10.2151/jmsj.79.1229

Miao J, Wang T, Wang H (2020) Interdecadal variations of the East Asian winter monsoon in CMIP5 preindustrial simulations. J Clim 33:559-575. https://doi.org/10.1175/jcli-d-19-0148.1

Parker D, Folland C, Scaife A, Knight J, Colman A, Baines P, Dong B (2007) Decadal to multidecadal variability and the climate change background. J Geophys Res 112:D18115. https://doi. org/10.1029/2007jd008411

Rayner NA (2003) Global analyses of sea surface temperature, sea ice, and night marine air temperature since the late nineteenth century. J Geophys Res. https://doi.org/10.1029/2002jd002670

Shi N, Feng GL, Gu JQ, Gu DJ, Yu JH (2007) Climatological variation of global cross-equatorial flows for the period 1948-2004. J Trop Meteor 13:201-204

Sui C-H, Chung P-H, Li T (2007) Interannual and interdecadal variability of the summertime western North Pacific subtropical high. Geophys Res Lett. https://doi.org/10.1029/2006g1029204

Walters D et al (2017) The Met Office Unified Model Global Atmosphere 6.0/6.1 and JULES Global Land 6.0/6.1 configurations. Geosci Model Dev 10:1487-1520. https://doi.org/10.5194/ gmd-10-1487-2017

Wang JZ, Li MC (1982) Cross-equator flow from Australia and monsoon over China. Scientia Atmos Sinica (in Chinese) 6:1-10

Wang WP, Yang XQ (2008) Variation of Somali jet and its impact on East Asian summer monsoon and associated China rainfall anomalies. Scientia Meteor Sinica (in Chinese) 28:139-146

Wang B, Ding Q, Fu X, Kang I, Jin K, Shukla J, Doblas-Reyes F (2005) Fundamental challenges in simulation and prediction of summer monsoon rainfall. Geophys Res Lett 32:L15711. https ://doi.org/10.1029/2005GL022734

Wang C, Lee S-K, Enfield DB (2008) Atlantic warm pool acting as a link between Atlantic multidecadal oscillation and Atlantic tropical cyclone activity. Geochem Geophys Geosyst. https:// doi.org/10.1029/2007gc001809

Wang B, Xiang B, Lee JY (2013) Subtropical high predictability establishes a promising way for monsoon and tropical storm predictions. PNAS 110:2718-2722. https://doi.org/10.1073/ pnas. 1214626110

Xiang B et al (2013) How can anomalous western North Pacific subtropical high intensify in late summer? Geophys Res Lett 40(10):2349-2354 
Xu Y (2011) The genesis of tropical cyclone Bilis (2000) associated with cross-equatorial surges. Adv Atmos Sci 28:665-681. https ://doi.org/10.1007/s00376-010-9142-z

Yu R, Zhou T (2007) Seasonality and three-dimensional structure of interdecadal change in the East Asian monsoon. J Clim 20:5344-5355. https://doi.org/10.1175/2007jcli1559.1

Zeng QC, Li JP (2002) Interactions between the Northern and Southern hemispheric atmospheres and the essence of Monsoon. Chin J Atmos Sci 26:207-226

Zeng G, Sun ZB, deng WT, Lin ZH, Li CH, (2011) Numerical simulation of SSTA impacts upon the interdecadal variation of the cross-equator flows in Eastern hemisphere. J Trop Meteor 27:223-232

Zhao X, Lu R (2020) Vertical structure of interannual variability in cross-equatorial flows over the Maritime Continent and Indian Ocean in boreal summer. Adv Atmos Sci 37:173-186. https:// doi.org/10.1007/s00376-019-9103-0
Zhao XP, Shen XY, Wang YQ, Zhu WD, Zhang GX (2012) The modulation of quasi-biweekly oscillation of cross-equatorial flow on typhoon tracks over the western North Pacific. Trans Atmos Sci 35:603-619 (in Chinese)

Zhu Y (2012) Variations of the summer Somali and Australia crossequatorial flows and the implications for the Asian summer monsoon. Adv Atmos Sci 29:509-518. https://doi.org/10.1007/s0037 6-011-1120-6

Publisher's Note Springer Nature remains neutral with regard to jurisdictional claims in published maps and institutional affiliations. 